\title{
Restoration of aged hematopoietic cells by their young counterparts through instructive microvesicles release
}

\author{
Steven J. Greco ${ }^{1,{ }^{*}}$, Seda Ayer ${ }^{1, *}$, Khadidiatou Guiro ${ }^{1,{ }^{*}}$, Garima Sinha ${ }^{1,2}$, Robert J. Donnelly ${ }^{3}$, \\ Markos H. El-Far ${ }^{1,2}$, Lauren S. Sherman ${ }^{1,2}$, Yannick Kenfack ${ }^{1,2}$, Sri Harika Pamarthi ${ }^{1}$, Marina \\ Gergues $^{1,2}$, Oleta A. Sandiford ${ }^{1,2}$, Michael J. Schonning ${ }^{2}$, Jean-Pierre Etchegaray ${ }^{3}$, Pranela \\ Rameshwar $^{1}$ \\ ${ }^{1}$ Department of Medicine, Rutgers New Jersey Medical School, Newark, NJ 07103, USA \\ ${ }^{2}$ Rutgers School of Graduate Studies, Rutgers New Jersey Medical School, Newark, NJ 07103, USA \\ ${ }^{3}$ Department of Biological Sciences, Rutgers University, Newark, NJ 07102, USA \\ ${ }^{*}$ Equal contribution
}

Correspondence to: Pranela Rameshwar; email: rameshwa@njms.rutgers.edu Keywords: age, hematopoiesis, bone marrow, miRNA, microvesicles

Received: September 24, 2021 Accepted: October 26, 2021

Published: November 11, 2021

Copyright: (c) 2021 Greco et al. This is an open access article distributed under the terms of the Creative Commons Attribution License (CC BY 3.0), which permits unrestricted use, distribution, and reproduction in any medium, provided the original author and source are credited.

\section{ABSTRACT}

This study addresses the potential to reverse age-associated morbidity by establishing methods to restore the aged hematopoietic system. Parabiotic animal models indicated that young secretome could restore aged tissues, leading us to establish a heterochronic transwell system with aged mobilized peripheral blood (MPB), co-cultured with young MPB or umbilical cord blood (UCB) cells. Functional studies and omics approaches indicate that the miRNA cargo of microvesicles (MVs) restores the aged hematopoietic system. The in vitro findings were validated in immune deficient (NSG) mice carrying an aged hematopoietic system, improving aged hallmarks such as increased lymphoid:myeloid ratio, decreased inflammation and cellular senescence. Elevated MYC and E2F pathways, and decreased p53 were key to hematopoietic restoration. These processes require four restorative miRs that target the genes for transcription/differentiation, namely PAX and phosphatase PPMIF. These miRs when introduced in aged cells were sufficient to restore the aged hematopoietic system in NSG mice. The aged MPBs were the drivers of their own restoration, as evidenced by the changes from distinct baseline miR profiles in MPBs and UCB to comparable expressions after exposure to aged MPBs. Restorative natural killer cells eliminated dormant breast cancer cells in vivo, indicating the broad relevance of this cellular paradigm - preventing and reversing age-associated disorders such as clearance of early malignancies and enhanced responses to vaccine and infection.

\section{INTRODUCTION}

Aging is a risk factor for chronic diseases, resulting in high morbidity, decreased quality of life and increased health care cost [1]. Over time, continuous intracellular stress leads to disrupted tissue physiology such as perturbated tissue homeostasis, stem cell exhaustion, and increased cellular senescence [2]. Cumulative ageassociated changes could be caused by external and replicative stress that alters the epigenetic dynamics [3].
These changes could predispose cells to oncogenic events, bypassing the default protection [4]. Outcomes of emerging drugs to reverse age underscore the complex aging process and demonstrate the challenge of using a single drug [5].

Age is associated with hematological disorders such as anemia, malignancies, reduced innate immune function and non-hematological disorder, e.g., diabetes and cardiovascular disease [6]. In the aged bone marrow 
(BM), the relationship between hematopoietic stem cells (HSCs) and their supporting niche cells such as stroma are functionally dysregulated $[7,8]$. The aging stromal cells release soluble and vesicular secretome to create an inflammatory milieu, increased cellular senescence and enhanced cell cycle [9, 10]. Increased numbers of HSCs in the aged are functionally impaired displaying features such as defective transplantability, loss of heterogeneity, increased genomic mutations, metabolic switch and myeloid bias [2, 8, 11-15]. Single driver mutation in the aged hematopoietic cells can lead to the emergence of non-malignant clones of indeterminate potential (CHIP) thereby increasing the risk of hematological malignancy [16]. The aged neural system could also influence BM functions, directly by innervation and indirectly by neurohormones [17-19].

The documented defects on hematopoietic aging have not been fully leveraged to reverse and/or halt the aging process [20]. Considering the expanded lifespan of humans, fulfilling this gap would have an impact on global public health and the economy. We propose an efficient and non-invasive therapeutic strategy that functionally restores the hematopoietic system. This method could be applied in preventive therapy for middle age individuals and as a potential treatment for the aged population [12]. Thus, restoring the aged hematopoietic system would improve the body's immune surveillance to eliminate emerging malignancies, effective response to infections and enhanced functions of other organs [21,22].

The seminal parabiotic models [23] were subsequently shown to improved cognitive, cardiac and skeletal muscle function of the older animals [24-28]. These parabiotic models as well as others employing partial cellular reprograming did not report on changes in the hematopoietic/immune systems [29]. Several studies indicated that there are precedents for hematopoietic rejuvenation. Young endothelial cells can reverse hematopoietic defects exerted by aged BM endothelial cells [30]. Dedifferentiated aged HSCs into iPSCs led to improved hematopoietic function [31]. Improved HSC function from atomic bomb survivors occurred when they were placed in a competent niche $[15,32]$. $\mathrm{Cdc} 42$ inhibitor was also reported to restore aged HSC function [33].

We developed a transwell system with aged and young hematopoietic cells that allowed for intercellular communication in a heterochronic system though their secretome. The heterochronic culture system showed restoration of the aged hematopoietic system by young mobilized peripheral blood (MPB) or umbilical cord blood (UCB), independent of allogeneic differences between the two donor cells. MiRNAs within secreted microvesicles (MVs) were responsible for the improved hematopoietic functions, through increased expression of MYC- and E2F- targeted genes, and decreased p53. The restoration paradigm in the heterochronic cultures were corroborated with immune deficient mice (NSG) carrying an aged human hematopoietic system, resulting in improved aging hallmarks - senescence, inflammation and increased lymphoid:myeloid ratio, similar to young humans [8]. Omics approaches identified the restorative miRNAs, which acted by regulating the genes for transcription/differentiation PAX and phosphatase PPMIF [34, 35]. These miRs were sufficient to restore the aged hematopoietic system in the NSG mice. Collectively, the results showed promise for age related disorders. Notably, enhanced natural killer (NK) activity in the restored aged cells were able to target dormant breast cancer cells in mice femurs, supporting the potential in age-related dysfunction such as malignancy [36]. We objectively discuss the implications for the hematopoietic restoration method in medicine.

\section{RESULTS}

\section{Hematopoietic restoration of aged mobilized peripheral blood cells (MPBs)}

MPBs are comprised of mixed cell subsets that include mature and immature hematopoietic cells. Furthermore, although the cellular frequency of particular cell subsets are different between young and aged MPBs, the compositions are similar. Thus, we evaluated these two sources of MPBs for baseline hematopoietic cells in clonogenic assays for CFU-GM (colony forming unitsgranulocytic monocytic) and BFU-E (burst forming units-early erythroid). There were similar numbers of CFU-GM between the two groups, but significantly $(p<0.05)$ less BFU-E in young MPBs (Supplementary Figure 1A). Flow cytometric analyses indicated comparable frequency of CD34+/CD38- cells (primitive hematopoietic cells) in the young and aged MPBs, but significantly $(p<0.05)$ more CD34+/CD38+ (progenitors) in young MPBs (Supplementary Figure 1B).

The hematopoietic effects by young MPBs on aged MPBs were studied in a transwell system in which the inner and outer wells contained equal amounts $\left(10^{7}\right)$ of young and aged MPBs, respectively (heterochronic culture) (Figure 1A). Control isochronic cultures contained aged or young MPBs in both wells. The 0.4 $\mu \mathrm{m}$ transwell membrane allowed for the passage of soluble factors and microvesicles (MVs), but prevented cell transfer [37] (Supplementary Figure 1C). The initial studies conducted a time-course investigation up to wk 5 using clonogenic assays for CFU-GM with the aged 
cells as readouts of hematopoietic activity. CFU-GM progenitors are excellent representation of hematopoietic activity in the samples. Controls included isochronic cultures with aged or young MPBs in both inner and outer wells. There was significantly $(p<0.05)$ more CFU-GMs with heterochronic cultures as compared to isochronic aged cultures but similar numbers $(p>0.05)$ with isochronic young cultures (Figure 1B). We also evaluated the phenotype of the restored aged cells and observed mature immune cells such as CD3 and NK cells (Supplementary Figures 1 and 6). These timeline studies combined with the phenotype shown at wk 7 led us to select the 7-day time point for subsequent studies.

The enhanced activity by hematopoietic progenitors (Figure 1B) led us to ask if similar outcome occurred at the level of HSCs. We performed long-term cultureinitiating cell (LTC-IC) assay in the outer wells of heterochronic cultures since this assay is an in vitro surrogate of HSC function [38]. Control isochronic cultures included young or aged cells in the inner and outer wells. At wks 1, 6 and 12, CFU-GMs in the outer wells of heterochronic cultures ( $n=8$, each in triplicate) were significantly $(p<0.05)$ increased, relative to isochronic aged cultures but were similar to isochronic young cultures (Figure 1C). Since CFU-GMs at wk 12 are derived from the seeded HSCs, their increase indicated increase in LTC-IC/HSC function with young cells.

\section{Hematopoietic restoration - independent of donor allogenicity}

We determined if allogeneic differences between the age and young donors influenced hematopoietic activity in the heterochronic cultures. Such possibility could occur by MHC-II transfer from the young cells to activate the immune cells within the aged cells [39, 40] (Supplementary Figure 1D). We addressed this question by asking if the restored aged cells stimulated their naïve counterparts (unrestored autologous cells). Oneway mixed lymphocyte reaction (MLR) with restore aged MPBs as stimulators and unrestored/freshly thawed aged autologous MPBs as responders, showed baseline stimulation, indicating no allogeneic influence by the young cells (Supplementary Figure 1E).

Next, we asked if MHC-II density on young cells could influence the restoration process. We used umbilical cord blood (UCB) as the source of young cells due to relatively higher MHC-II on their HSCs, which we corroborated in our samples [41] (Supplementary Figure 1F). Parallel heterochronic cultures with UCB or young MPBs and the same aged cells indicated significantly $(p$ $<0.05$ ) more CFU-GM with UCB, relative to isochronic aged cultures, but significantly $(p<0.05)$ less than young MPBs (Figure 1D). One-way MLR with UCB showed no allogeneic response (Supplementary Figure 1G).

MVs can transfer MHC-II leading us to examine these MVs for MHC-II [37, 42]. Flow cytometry for MHC-II on heterochronic MVs indicated background fluorescence whereas the positive control (activated peripheral blood mononuclear cells) showed bright fluorescence (Supplementary Figure $1 \mathrm{H}$ and 1I). Together, the data indicated that allogeneic difference between the young and aged cells did not contribute to aged cell restoration.

\section{Improved senescence of aged cells in heterochronic cultures}

Cellular senescence is an established aging hallmark, which prompted us to ask if the heterochronic cultures improved the senescence gene profile of these cells $[10,43]$. Senescence gene arrays (84PCR), using a 4-fold cutoff, indicated $85 \%$ increase for unrestored/baseline aged cells and $43 \%$ for restored cells (Figure 1E, 1F, Supplementary Figure $2 \mathrm{~A}$ and $2 \mathrm{~B}$ ). The values were similar with variations for each time point, $\pm 10^{3}$. Since the purpose of the studies was to evaluate the changes in senescence genes, we plotted the averages in the scatter plot. Similar analyses with senescence secretome arrays (SASP, 68 antibodies) identified 13 proteins in the media of baseline aged cells and 4 with in the media of heterochronic/restored cultures [44] (Supplementary Figure $2 \mathrm{C}-2 \mathrm{G})$. Collectively, the restoration paradigm improved the senescence gene profile of aged MPBs.

\section{Molecular changes - amenable to balanced hematopoietic activity}

The vast difference in oxidative stress between young and aged samples (Figure 1G) led us to further analyze the senescence PCR data. Hierarchical clustering using the averages from biological replicates indicated striking similarities between young and restored MPBs (Figure 1H). A cluster of 30 expressed genes (Boxed region), when subjected to RNA-protein analysis (RAIN), showed a gene network comprised of hematopoietic regulatory programs (Figure 1I, Supplementary Figure $2 \mathrm{H})$. Including is MDM2 expression that can decrease p53, which is consistent with improved senescence profile in the restored samples. Decreased p53 would not compromise DNA repair due to CHEK1/2 within the network [45]. Upregulated IGF1, which is associated with longevity, was increased in the restored cells [46]. Decreased fibronectin (FN1) in the restored cells could improve risk for hematopoietic pathology such as myelofibrosis [47]. 


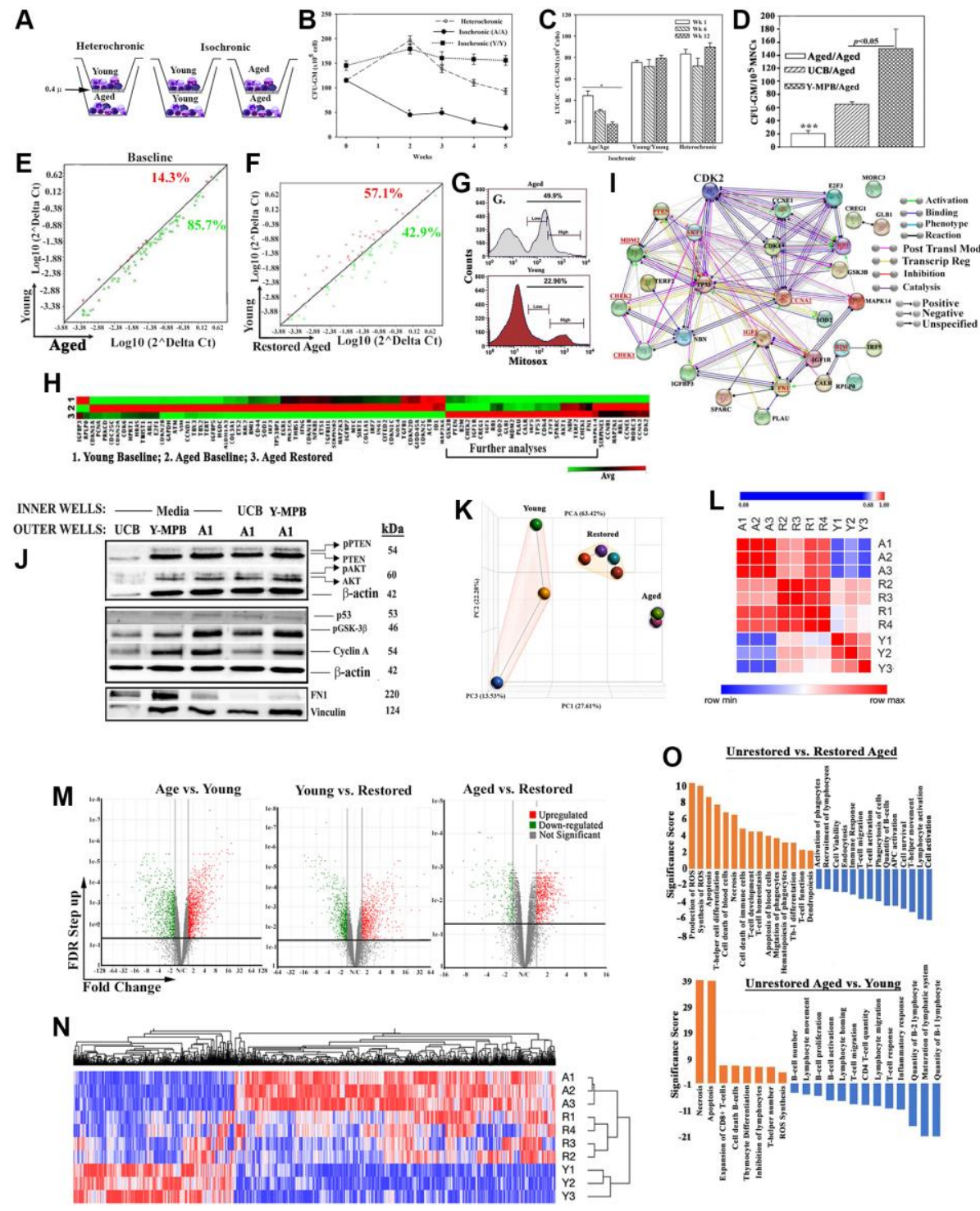

Figure 1. In vitro hematopoietic restoration of aged MPBs. (A) Cartoon shows the method employed for non-contact isochronic and heterochronic cultures. (B) Timeline clonogenic assays for CFU-GM with viable cells from isochronic (aged or young MPBs) and heterochronic cultures (restored aged MPBs). The results are presented as mean CFU-GM \pm SD $(n=8$ donors, each donor tested in triplicate with two young donors). ${ }^{*} p<0.05$ vs. similar time points in heterochronic cultures; ${ }^{* *} p<0.05$ vs. time 0 and wks 2,3 and 4 . (C) LTC-IC cultures were established using the model in ' $A$ ' except for seeding the aged MPBs on confluent $\gamma$-irradiated BM stromal cells in the outer wells. Control cultures contained isochronic young or aged cells in both wells. At wks 1, 6 and 12, clonogenic assay for CFU-GM with aliquots of viable mononuclear cells. The values for each time point were plotted together ( 8 donors, each tested in triplicates, CFU$\mathrm{GM} / 10^{5} \mathrm{MPBs} \pm \mathrm{SD} .{ }^{*} p<0.05$ vs. heterochronic. (D) Heterochronic and isochronic cultures were established with $10^{7} \mathrm{UCB}$ in the inner wells. At wk 4, aliquots of aged MPBs were analyzed for CFU-GM and the results presented as mean CFU-GM \pm SD for 5 different UCB, each tested in duplicate. ${ }^{* * *} p<0.05$ vs. heterochronic cultures with UCB. (E) Senescence-related gene expression was performed with 84-gene qPCR arrays using cDNA from restored and unrestored (baseline) aged and young MPBs. Gene expression for 4 donors was determined by calculating the $\Delta C_{t}$ between gene-of-interest and housekeeping genes and then plotted as $\log _{10}\left(2^{\Delta C t}\right)$. Each dot represents the average gene expression for donors. Baseline comparison for unrestored young vs. aged MPBs is shown in red for higher expression in young and green for higher expression in aged. The line $y=x$ indicates no change. (F) The analyses described in ' $E$ ' was performed for young and restored and the data are similarly presented. (G) Oxidative stress by MitoSox assay, delineated as MitoSox, negative, low and high by flow cytometry. (H) Hierarchical clustering with the array data from ' $E$ and $F^{\prime}$. (I) The genes upregulated in the qPCR array in ' $H$ ' (open boxed region) were analyzed by RAIN to demonstrate predicted interactions. (J) Western blot (3 biological replicates) with whole cell extracts from unrestored young MPB (Y), UCB and restored A1 (restored with UCB or Y-MPB). SDS-PAGE: top, 15\%; middle 12\%; bottom, 6\%. (K) PCA of RNA-Seq data from MPB (3 young, 3 age) and 4 restored MPBs. Lines highlight the groups. (L) Similarity matrix of ' $A$ ' for young, age and restored samples. (M) Volcano plot of differentially expressed genes. (N) Heatmap of fold changes with an FDR $\leq 0.05$ as a cut off with linked significant pathways. (O) IPA-determined significant hematological functions with shown comparisons. See also Supplementary Table 1, Supplementary Figures 1 and 2. 
We validated key proteins within the network (Figure 1Iunderline) by Western blot using extracts from aged cells (Figure 1J, densitometric analyses, Supplementary Figure 2I). Increases in p-PTEN and p-AKT in the restored cells are amenable to balanced cell proliferation; increased cyclin A can decrease G2 transition to maintain hematopoietic cell quiescence; higher GSK-3 $\beta$ suggested a pathway involving $\beta$-catenin to benefit hematopoietic function. Consistent with increased MDM2 in the PCR array was decreased p53 protein (Supplementary Figure 2I). In summary, hematopoietic restoration is associated with decreased senescence and increased expression of genes to benefit hematopoietic activity.

\section{Molecular landscape in unrestored versus age restored MPBs}

We examined global changes with RNA-Seq by comparing the following: restored and unrestored age cells, and young MPBs. Principle component analyses (PCA) showed distinct clustering among the groups (Figure 1K). Although one young donor was not within the cluster of the other two young donors, similarity matrix showed the restored samples moving closer to the young profile (Figure 1L). Applying a false discovery rate (FDR) cutoff of $<0.05$, we selected 2,140 genes, visualized in volcano plots and hierarchical clustering (Figure $1 \mathrm{M}$ and $1 \mathrm{~N}$ ). Since the hierarchical plot was established with $>2,000$ genes, we conducted additional analyses to understand the molecular changes with the restored aged MPBs.

Ingenuity pathway analyses (IPA) identified top pathways associated with hematopoietic development and, decreases in reactive oxygen species, apoptosis and necrosis (Figure 1O). Gene Set Enrichment Analysis (GSEA) identified significantly up- and down-regulated (FDR $q$ value < 0.05) pathways in age and young groups (Figure 2A and 2B). MYC pathways were the only downregulated targets in the age group with 14 upregulated pathways. Restoration improved key agerelated functions - inflammation, immune suppression and cell death - TNF $\alpha$ signaling, NFKB signaling, apoptosis and p53. The Venn diagram depicts the pathways corrected by restoration along with the shared and unique pathways (Figure 2C). The up- and downregulated pathways in the aged samples transitioned into the overlapping section with young following restoration. Heatmaps are shown for the enriched sections of the top shared pathways (Figure 2D and Supplementary Figure 2J).

\section{MYC, E2F and p53 in hematopoietic restoration}

This section validated key pathways identified in the RNA-Seq analyses. MYC pathway, which was increased with restoration could explain hematopoietic restoration by partial reprogramming $[29,48]$. E2F, due to its role in cell cycle regulation, which is important for hematopoietic homeostasis. We selected p53 because of increased MDM2 in the restored cells (Figure 1I, $1 \mathrm{~J}$ and 1O). Reduced p53 would mitigate cellular senescence. Heterochronic cultures, in the presence or absence of MYC, E2F or MDM2 inhibitors or vehicle, indicated decreases in proteins linked to G1 transition by Western blot (Figure 2E and 2F). Clonogenic assay for CFU-GM in the cultures showed significant $(p<0.05)$ decreases with the inhibitors relative to vehicle (Figure 2G). In summary, decreased p53, and increases in MYC and E2F pathways are important for restoring the function of aged MPBs.

\section{In vivo restoration of the aged hematopoietic system - humanized NSG (huNSG)}

This section recapitulated the in vitro restoration in huNSG mice carrying aged hematopoietic system. We achieved hematopoietic chimera in NSG mice by transplanting aged CD34+ cells using dose-response and time-course studies. Mice began to achieve chimera after 8 weeks, based on human CD45+ cells in mice blood (Supplementary Figure 3A and 3B, depicted baseline chimerism prior to the second transplant). Mice with stable chimera (wk 19) were transplanted with CD3-depleted restored MPBs. Mice remained healthy until the end-point (Figure 2H, Supplementary Figure $3 \mathrm{C}-3 \mathrm{H})$. After wk 14, we analyzed the blood, spleen and $\mathrm{BM}$ of mice for immune cells by flow cytometry (Supplementary Figure 3I-3N). Mice transplanted with restored cells showed significantly $(p<0.05)$ more huCD3 and huCD34+ cells, decreased myeloid cells and increased lymphoid:myeloid ratio, as compared to mice given unrestored aged cells (Figure 2I-2L). Clonogenic assays for CFU-GM using huCD45+ cells from mice femurs indicated a significant $(p<0.05)$ increase when mice were given restored cells as compared to those given unrestored aged cells (Figure 2M). These improvements correlated with enhancement in senescence profile: plasma, $12 \%$ restored vs. unrestored cells; qPCR senescence/aging array with femur cells, $8 \%$, restored cells vs. unrestored cells (Figure $2 \mathrm{~N}$ and 2O, Supplementary Figure 3O-3Q).

We assessed the functional competence of HSCs by selecting CD34+ cells from the experimental mice and transplanting into naïve NSG mice. CD34+ cells from mice with restored cells reconstituted NSG mice at week 8 whereas similar transplant with CD34+ cells from mice given aged cells did not achieve chimera (Figure $3 \mathrm{~A}$ and $3 \mathrm{~B}$ ). In summary, transplantation of in vitro restored cells improved hematopoietic function in NSG mice carrying an autologous aged hematopoietic system. 


\section{Microvesicles (MVs) in aged hematopoietic restoration}

Secreted MVs with their RNA, protein and lipid cargo could cross the culture membrane to establish communication between the aged and young cells [37, 49]. Also, MVs can regulate hematopoiesis [50]. We therefore determined if MVs, in particular exosomes, could be responsible for restoration of aged MPBs. We characterized the MVs from heterochronic and isochronic cultures and found similar size (Supplementary Figure 4A). Notably, aged MPBs produced higher number of MVs as compared to those
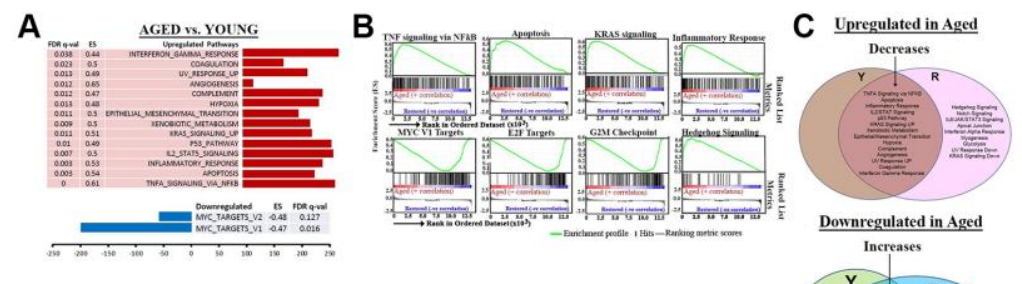

D

TNFA Signaling via NFKB
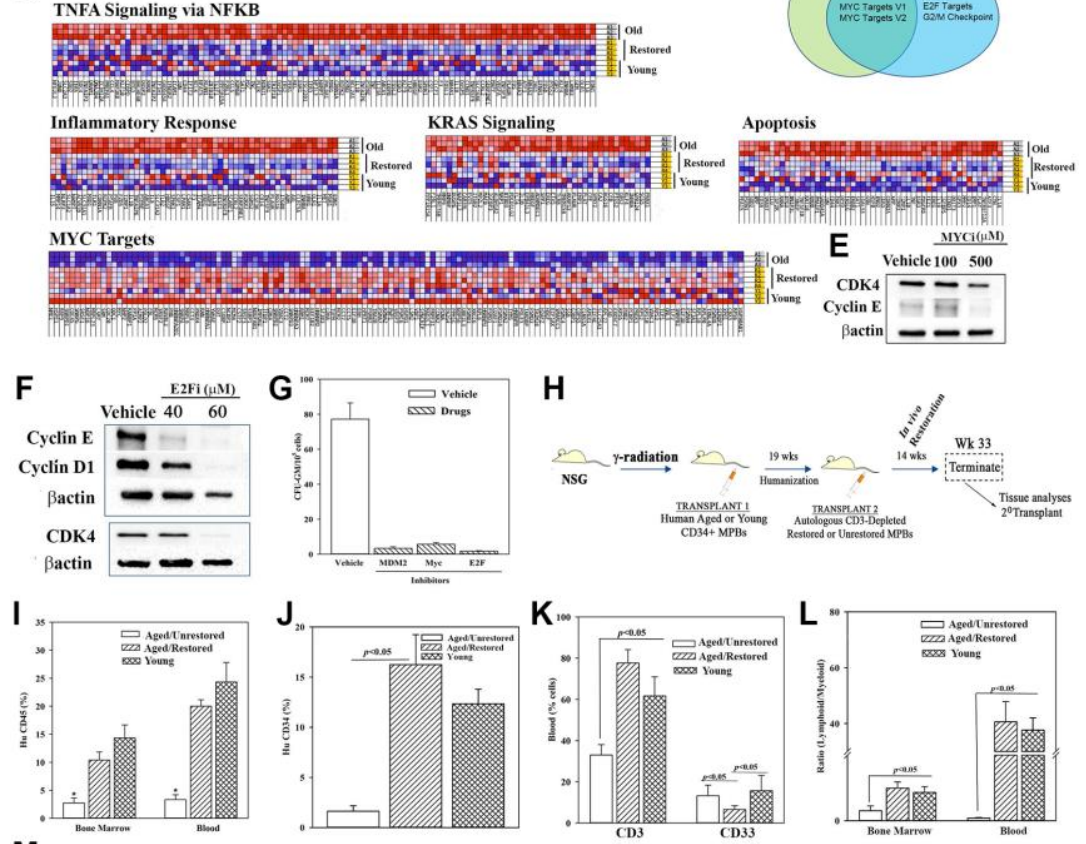

M
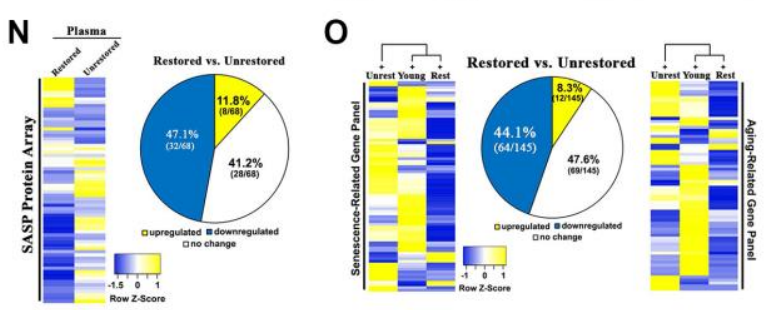

Figure 2. Molecular changes in age-related pathways following restoration. (A) Up-and down-regulated pathways in age, relative to young MPBs. (B) Enrichment plots for the top and down-regulated pathways. (C) Venn diagram shows shared and unique pathways between young and restored group, and overlap, changed pathways with restoration. (D) Enriched heatmaps of significant changes in ' $G$ ' (Full heat maps Supplementary Figure 2J). (E, F) Western blot for cell cycle proteins with extracts from 3 restored cells, MYC or E2F inhibitors or vehicle. (G) Clonogenic assay for CFU-GM with cells restored with $1 \mu \mathrm{M}$ MDM2, $100 \mu \mathrm{M}$ MYC or $40 \mu \mathrm{M}$ E2F, mean \pm SD (4 different aged donors, restored with 2 young donors; each in triplicates). See also Supplementary Figure 2). (H) Overview of NSG transplanted with aged huCD34+ MPBs. At the achievement of chimera, NSG with an aged hematopoietic system are injected with autologous restored $(n=12)$ or unrestored $(n=11)$ CD3-depleted MPBs. Serial transplantation used wk 33 huCD34+ cells. Controls were given young CD34+ cells $(n=8)$. (I-K) Flow cytometry for huCD45+ cells in BM and blood, ${ }^{*} p<0.05$ vs. the other groups, (I), huCD34+ cells in $\mathrm{BM}(\mathrm{J})$, huCD3+ and huCD33+ cells in blood (K), mean \% cells \pm SD. (L) Lymphoid (CD3+ ${ }^{+}$CD19+)/myeloid (CD33 ${ }^{+}$) ratio in BM and blood. (M) CFU-GM in cultures with huGM-CSF and hulL-3 and huCD45+ cells from BM, mean \pm SD. (N) SASF array with huNSG plasma. Semiquantitative densitometry used 1.5-fold cutoff for classification as up- or down-regulated, or no change. Heatmaps and piechart for differential gene expression. (0) RNA from huCD45+ BM cells evaluated qPCR gene arrays. Normalization to housekeeping genes used 1.5fold cutoff, mean \pm SEM. ${ }^{*} p \leq 0.05$ vs. control. See also Supplementary Figures 2 and 3 . 
released from heterochronic cultures or young MPBs (Supplementary Figure 4B). We also validated the incorporation of MVs into aged cells by added those from day 3 heterochronic cultures to naïve aged cells. The MVs, labeled with CMAC blue dye, were examined for transfer into the aged cells by 2D (EVOS imaging) and 3D (confocal microscopy) imaging (Supplementary Figure 4C; Supplementary Videos 1 and 2).

We tested the role of MVs in aged hematopoietic restoration by pooling those from day 4 and 7 heterochronic cultures. The pooled MVs $\left(10^{6}\right.$ particles, based on dose response studies) were added to naïve aged MPBs at seeding (time 0) and after 4 days. After 7 days, clonogenic assay for CFU-GMs indicated significantly $(p<0.05)$ more colonies with MVs from heterochronic cultures, relative to those from isochronic young and aged cultures, solidifying a role for MVs in hematopoietic restoration (Figure 3C).

We sought the candidate MV cargo by assessing the RNA content, which was higher in young MPBs as compared to aged MPBs (Figure 3D). We focused on miRNAs due to their role in hematopoiesis [51]. The pharmacological agent, BCI-137 (AGO2 inhibitor), blunted miRNA packaging during MV biogenesis without compromising their release (Supplementary Figure 4D, 4E). BCI-137 reduced the small RNA contents of $\mathrm{MVs}$, including significant $(p<0.05)$ decrease of miRs, and decreased CFU-GM in the heterochronic cultures (Supplementary Figures 4F, 4G and $3 \mathrm{E}, 3 \mathrm{~F})$. These findings indicated a critical role for the miRNA content of MV in aged hematopoietic restoration.

We sought the causative miRNA(s) using an 84-probe array. MVs from isochronic (young and aged) and heterochronic co-cultures showed distinct miR profiles with 25 shared among the groups (Figure $3 \mathrm{~F}$ and $3 \mathrm{G}$ ). IPA predicted targets for the differentially expressed miRs and indicated a functional network in which young miRs are poised to prevent aging disorders such as cancer and hematological disorders (Supplementary Figure 4H). MiR-19a, -103a, -106b and -146a were upregulated in the young and restored MVs. Since qPCR only validated miR-19a in the young and restored cells (Figure $3 \mathrm{H}$ ), we conducted further analyses by RNA-Seq of small RNA within the MVs. Using an expression cut-off of 100 mappable reads, we identified 13 and 17 unique miRs in aged and young MVs, respectively (Figure 3I). 12/17 miRs were higher in young vs. aged, while 3/17 were lower (Figure 3I, middle). The miRnome of MVs from UCB was vastly different with 70 miRs in $>100$ mapped reads but only 4 shared with young MPBs (Supplementary Figure 4I).
Similarly, there were differences in intracellular miRnomes among aged, young, and UCB (Supplementary Figure 4J). Importantly, after restoration with young MPBs or UCB cells, there were common miR profiles in the heterochronic cultures, indicating that aged cells could be driving the MV cargo secreted from young cells (Figure 3J-3K, Supplementary Figure 4K-4O).

Among the 12 differentially expressed miRs between baseline young and aged MPBs, 8 were upregulated in the restored cells (Figure 3I and 3L). We validated the 12 miRs by qPCR, which were normalized with miR7641-2 due to equal expression among the groups. These studies verified $6 / 12$ miRs (Figure $3 \mathrm{~L}$, middle/M, Supplementary Figure 4M-4O). We then asked if the restored cells release MVs containing the validated miRs. To address this, we washed and then transferred the restored aged cells to the inner wells as facilitator young cells in heterochronic cultures (Supplementary Figure 4P). The MVs in these heterochronic cultures indicated the continued presence of miR-223 and -619 (Supplementary Figure 4P).

We performed cause-effect studies by expressing $\geq 1$ of the $6 \mathrm{miRs}$ in aged MPBs. These transfected cells were placed in cultures for 7 days, similar to the transwell cultures. Specifically, we cultured the aged cells to mimic restoration with young MPBs, except that these cultures dissected the restorative effects of specific miRNAs. After the culture period, we performed clonogenic assays for CFU-GM and noted significant $(p<0.05)$ increase in CFU-GM with miR-619 and/or -1303 , and in combination with the other miRs (Figure 3N). Thus, miR-619, -1303 and -4497 became the restorative candidates for subsequent studies.

\section{Downstream targets of restorative miRNAs}

In order to understand how the MV-containing restorative miRs regulate hematopoietic restoration, we mapped the downstream effector pathways. First, we determined how miRs within the young MVs, and restored (heterochronic) or unrestored (isochronic) aged cells interact to cause functional changes. The miR interactome identified the top cellular pathways, including T-helper 1 and 2, cellular development and molecules that regulate senescence, e.g., CDKN2A and p53 (Figure 4A, Supplementary Figure 4Q and 4R). The greatest convergence between the two datasets was $\mathrm{p} 53$ (Figure 4B, orange lines). This outcome is in line with our studies showing p53 with a major role in hematopoietic restoration (Figures 1 and 2). We observed similar findings with the dataset from MVs released from heterochronic cultures using UCB (Supplementary Figure 4S-4V). 
We applied miRNA target prediction software for direct targets of the 6 restorative miRNAs. Predicted targets (6101) for the individual miRNAs were stratified for common targets if they include the 6 miRs (Figure 4C).
After this, we narrowed the targets if they share $>3 \mathrm{miR}$ hits and these hits must include the restorative miR-619 and -1303 (Figure 3). The remaining targets were scanned for known expression in relevant tissues. We
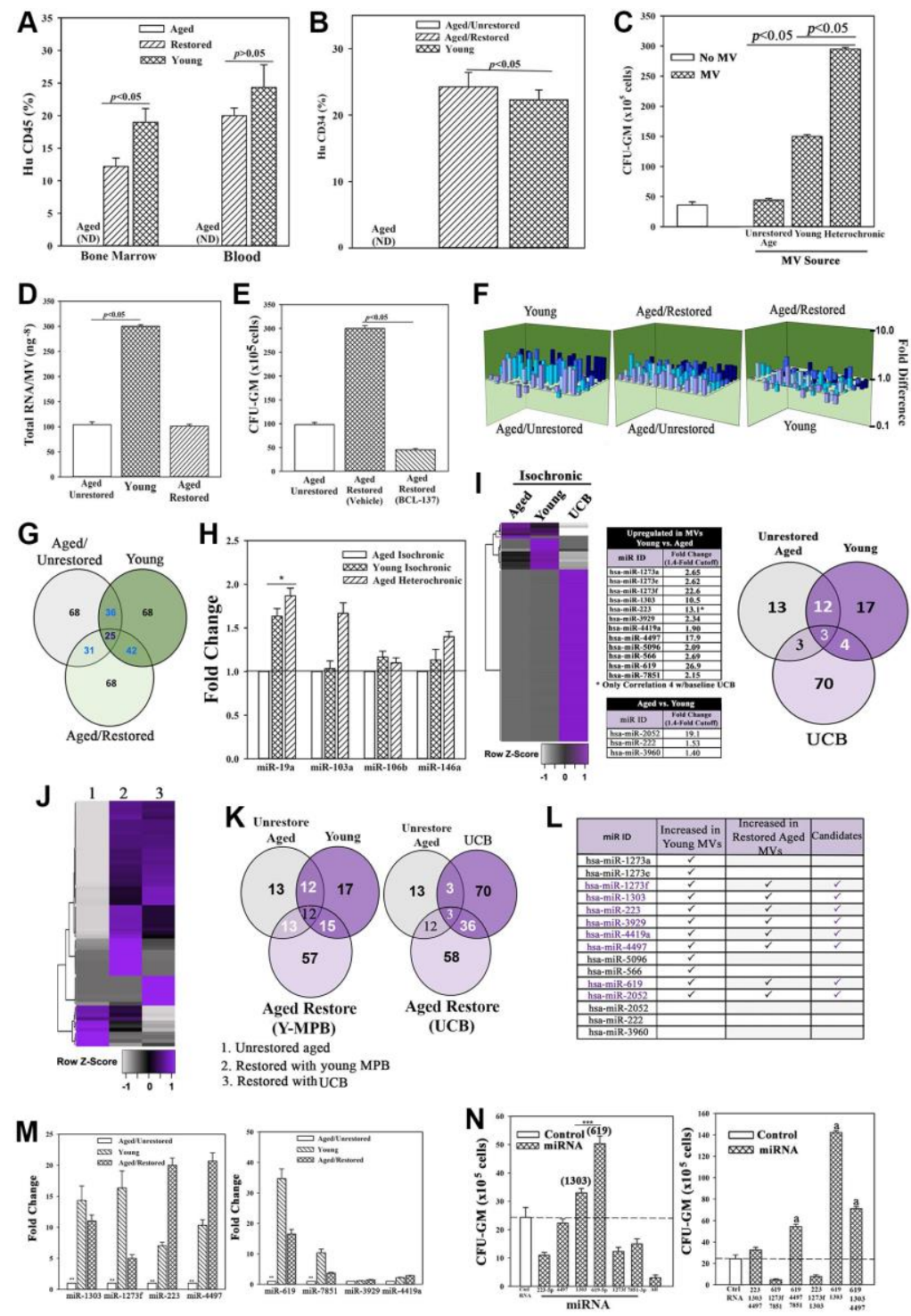

Figure 3. Restored cells transplanted in NSG mice with aged human hematopoietic system (huNSG) and exosomal RNA in restoration. (A and B) HuCD34+ cells $\left(10^{5}\right)$, pooled from wk 33 mice (Figure $2 \mathrm{H}$ ) were injected into naïve NSG mice $(n=3)$. At 12 wks, mice were analyzed for huCD45+ and huCD34+ cells. ND = none detected. (C) Pooled MVs $\left(10^{6}\right)$ from heterochronic or isochronic (young and aged) cultures were added to naïve aged MPBs on day 0 and 4 and at day 7, CFU-GMs were assessed in clonogenic assays, mean \pm SD, $n=5$. (D) Total RNA in MVs isolated from heterochronic cultures, $\mathrm{ng}^{-8} / \mathrm{MV} \pm \mathrm{SD}, n=8$. (E) $\mathrm{BCl}-137$ or vehicle was added to heterochronic or isochronic cultures, CFU-GM $\pm S D, n=5$. (F) 3D plots with data from qPCR miR array data using RNA from MVs. (G) Venn diagram showing differential and overlapping miRNAs. (H) qPCR for differentially expressed MV miRs. Shown are the consistently upregulated miR in young isochronic (dark green bar) and heterochronic cultures (striped bar), mean $\pm \mathrm{SD}, n=3$. Aged isochronic cultures were assigned a value of 1 . ${ }^{*} p \leq 0.05$ vs. control. (I) MiRnome sequencing used small RNA from MVs of aged and young MPBs or UCB. Heatmaps used miRNA, > 1.4-fold between aged and young samples. Venn diagrams depicts the differential and overlapping miRNAs. (J, K) Studies, similar to ' $I$ ', compared miRNAs, sequenced from MVs of aged isochronic and heterochronic (cultured with young MPB or UCB) samples. (L) The 12 miRs showing differential expression between aged and young in ' $I$ ' were compared to miRs that were increased in heterochronic vs. aged isochronic cultures (I, J). Shown are the increased 8 miRs in restored cells. (M) qPCR for the 8 miRs, 7 biological replicates, each in triplicate. The data are normalized to miR-7641-2 and presented as fold change using 1 for aged control. (N) 6 validated miRs or control miRs were expressed, alone (left) or together (right) in 5 biological replicates, each in triplicate. CFU-GM at day 7 , mean \pm SD. ${ }^{*} p \leq 0.05$ vs. control. See also Supplementary Figures 3 and 4. 
eliminated targets encoding hypothetical proteins and if their expression was restricted to neural tissues. We then subjected the targets to predicted pathway analysis (Figure 4D, brown) in the context of our effector-target interactome (Figure 4D - blue and light orange, 4E). The resulting 5 target candidates included the transcription/differentiation PAX5, which was increased in the unrestored isochronic cells, but significantly $(p<$ 0.05) decrease after restoration (Figure 4F and 4G) [34]. Both PAX5 and phosphatase PPM1F, which is linked to integrin-mediated adhesion, were decreased in the femurs of restored mice (Figure 4H) [35]. These results led us to examine baseline expression of PAX5 and PPMIF. The results indicated consistent increase in PAX5 in the aged cells, but decrease in PPM1F, perhaps due to its complex function (Figure 4I).

We performed cause-effect studies between the restorative miRs and PAX5/PPM1F expression by transfecting the aged MPBs with pre-miR-619 or pre1303 and -4497 (combo) or miR mimic (control). Analyses for PAX5 and PPM1F mRNA by qPCR indicated that miR-combo significantly $(p<0.05)$ decreased PAX5 and PPM1F mRNAs, compared to control or pre-miR-619 alone (Figure 4J). In corollary studies, we transfected young MPBs with anti-miR-619 or anti-miR (Combo) and observed increases in both PAX5 and PPM1F with miR-619 (Figure 4K).

Functional studies used aged MPBs, transfected with PAX5 or PPMIF siRNA or scramble siRNA followed by clonogenic assay for CFU-GM. PAX 5 siRNA caused a significant $(p<0.05)$ decrease in CFU-GM whereas PPM1F siRNA significantly $(p<0.05)$ increased CFUGM (Figure 4L). Positive control with heterochronic cultures resulted in the expected colonies. Knockdown of PAX5 and PPM1F led to T-cell activation, which is in line with improved lymphoid functions during restoration (Figure 4M).

\section{In vivo hematopoietic restoration by candidate miRNAs}

We asked if the restorative miRs (-619 and/or $-1303+$ -4497 (combo)) (Figure 3) could replace cellular in vitro restoration in heterochronic cultures. We addressed this by transplanting aged MPBs, transfected with the restorative miRs in NSG mice carrying aged hematopoietic system (Figure 5A). We selected mice with $>1 \%$ blood chimera (huCD45+) to transplant aged MPBs that were transfected with miR-combo, miR-619 or control miR mimic (Supplementary Figure 5A and 5B). The mice showed normal pathology (Supplementary Figure $5 \mathrm{C}-5 \mathrm{H})$. Compare to control miR, there was significantly $(p>0.05)$ more huCD45+ in the BM of mice with cells transfected with the restorative miRs (Figure
5B). Relative to control miR, miR-619 transfectants resulted in significantly $(p<0.05)$ more CD3+ and CD4+ cells and significant $(p<0.5)$ decrease of CD8+ cells (Figure 5C). The lymphoid:myeloid ratio, which is a hallmark of reverse aging was increased, with significant $(p<0.05)$ increase of CD19+ cells and decreased $(p<$ 0.05) CD33+ myeloid cells (Figure 5D-5F).

Clonogenic assay for CFU-GM using huCD45+ cells from mice femur indicated significant $(p<0.05)$ increase when mice were given miR-combo- or miR619-transfected aged cells as compared to the group given control miR mimic (Figure 5G). PAX5 level was significantly $(p<0.05)$ decrease in mice with miR-619 or miR-combo transfectants (Figure 5H). Similar decrease was observed for PPM1F, but only for miRcombo (Figure 5H).

The miR-mediated restoration also reduced cellular senescence, based on PCR array with cDNA from huCD45+ femur cells (Figure 5I, Supplementary Figure $5 \mathrm{I}-5 \mathrm{~K})$. MiR-combo significantly $(p<0.05)$ decreased $(>50 \%)$ the senescence/age-related genes. SASP factors in mice plasma showed $51.4 \%$ and $45.6 \%$ decreases for miR-619 and miR-combo, respectively (Figure 5J). Taken together, the miRs restored hematopoiesis similar to cells from heterochronic co-cultures, and highlighted roles for the transcription factors PAX5 and PPM1F in restoration.

\section{Enhanced Natural killer (NK) activity within restored old MPB in immune therapy}

Age-related defects in NK cells can compromise surveillance for emerging malignancy, infection and induce cell senescence [36, 52]. We asked if the restoration process corrected the age-linked NK defects. Flow cytometry indicated 8-fold more CD56+ cells within the restored cells, relative to unrestored cells (Figure 6A). This correlated with significant $(p<0.05)$ increase in Lytic Units (Supplementary Figure 6A) in 3/4 aged restored cells (Figure 6B).

We further examined the function of the restored NK cells. We selected a model of dormant breast cancer (BC) cells (BCCs) in nude BALB/c [53] (Figure 6C). At 1 month, the mice with CD3-depleted restored MPBs were chimeric for human hematopoietic function with no evidence of lethargy, no palpable lymph node and comparable survival between groups (Figure 6D-6G). Since the BCCs were transfected with pOct4a-GFP, we evaluated the mice femurs for GFP by qPCR. The results indicated 6 folds more GFP+ cells in mice given unrestored MPBs, related to mice with restored aged MPBs (Figure 6H). We did not detect GFP+ cells in the blood, indicating that the dormant cells remained in the 
femur (Supplementary Figure 6B and 6C). Together, these findings showed the restored MPBs capable of clearing dormant BCCs in the BM.

Since the dormant BCCs were cleared in nude mice, we performed cause-effect studies to determine if restoration of NK functions could explain the dramatic decrease in BCCs. First, we performed in vitro studies by coculturing BC stem cells (CSCs/GFP+) with restored aged MPBs, with or without NK cells (Supplementary Figure $6 \mathrm{D})$. The number of GFP+/CSCs was significantly ( $p<$ $0.05)$ reduced with NK-containing restored MPBs as
A

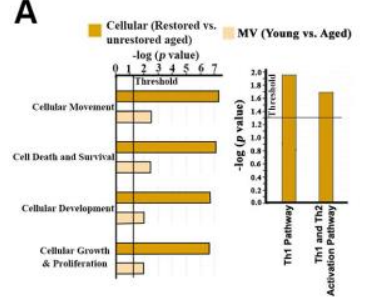

E

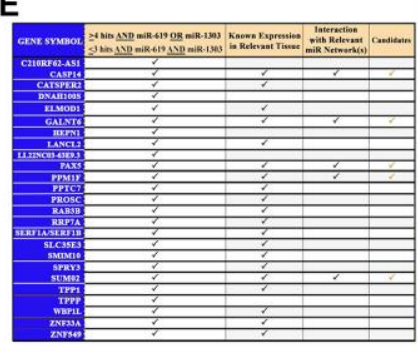

G

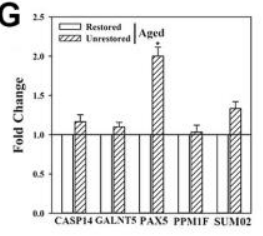

K

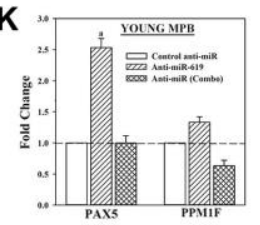

B

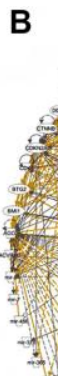

C

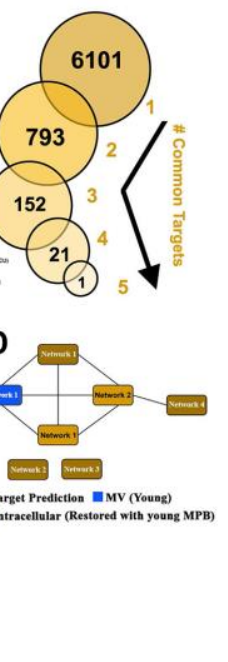

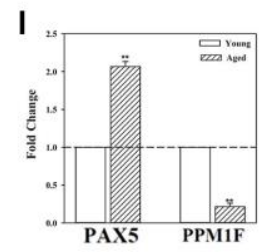

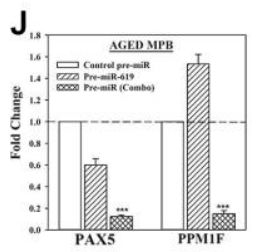

$\mathbf{M}$
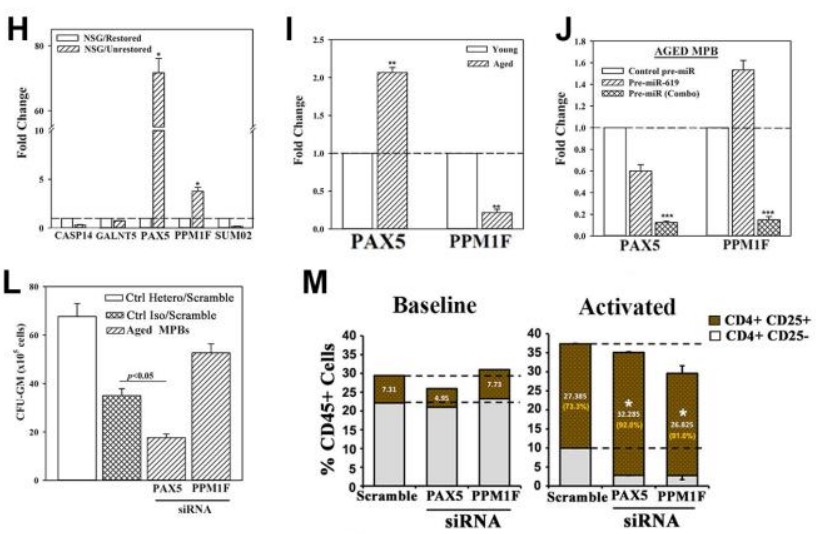

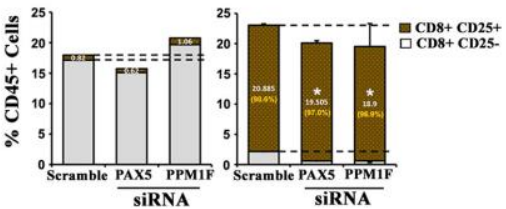

Figure 4. Exosomal miRNA targets in restoration. (A) IPA output of top predicted cellular functions (left) and canonical pathways (right) in analyses of MV miRNAs from the following: young vs. aged cells, heterochronic vs. aged isochronic cultures. (B) Radial depiction of young MV vs. restored intracellular interactome with p53 at the center of overlapping networks (Orange, direct interactions). (C) Analyses of 6 miRNAs (Figure 4L) for targets using TargetScan human database. (D) Targets were analyzed by IPA and the predicted networks (brown) compared to the young exosomal (blue) and aged heterochronic intracellular (dark orange) miRNA interactome. (E) Tabulation of selected targets and predicted interaction with the miRNA interactome. (F) 5 potential downstream targets for functional validation. (G, H) qPCR for candidate targets using RNA from aged cells of heterochronic or isochronic cultures (G), or human cells from femurs of huNSG (H), Fold change of normalized ( $\beta$-actin) results, $n=4$. (I) qPCR for PAX5 and PPM1F in aged and young MPBs, fold change with young donor assigned 1. (J, K) Aged MPBs were transfected with pre-miRs or control miR (J) and young MPBs, with anti-miRs or control miR (K). At day 7 , the cells were analyzed for PAX5 and PPM1F mRNA by qPCR. The data are presented as the mean \pm SD fold change, $n=4$. The controls were assigned values of 1. (L) Aged MPBs were transfected with PAX5 or PPM1F siRNA or scramble (control). At day 7, the cells were analyzed for CFU-GM. Positive ctrl: heterochronic cultures, mean CFU-GM $\pm \mathrm{SD}, n=4$. (M) Effect of PAX5 or PPM1F knockdown by siRNA on T-cell activation (CD25) for $\mathrm{CD}^{+}$(top panels) and $\mathrm{CD}^{+}$(bottom panels) populations. Right panels represent the \% activated vs. total T-cells shown in orange. See also Supplementary Figure 4. 
compared to NK-depletion (Figure 6I). Adapting these studies in NSG mice (Figure 6J), we could not detect $\mathrm{GFP}+$ cells in mice given restored $\mathrm{NK}+$ cells whereas control mice (baseline) and mice given $\mathrm{NK}$ - restored cells showed dormant CSCs (green) in femurs (Figure $6 \mathrm{~K}-6 \mathrm{~N})$. In summary, NK cells in restored MPBs effectively targeted and mostly cleared dormant BCCs in vivo.

A
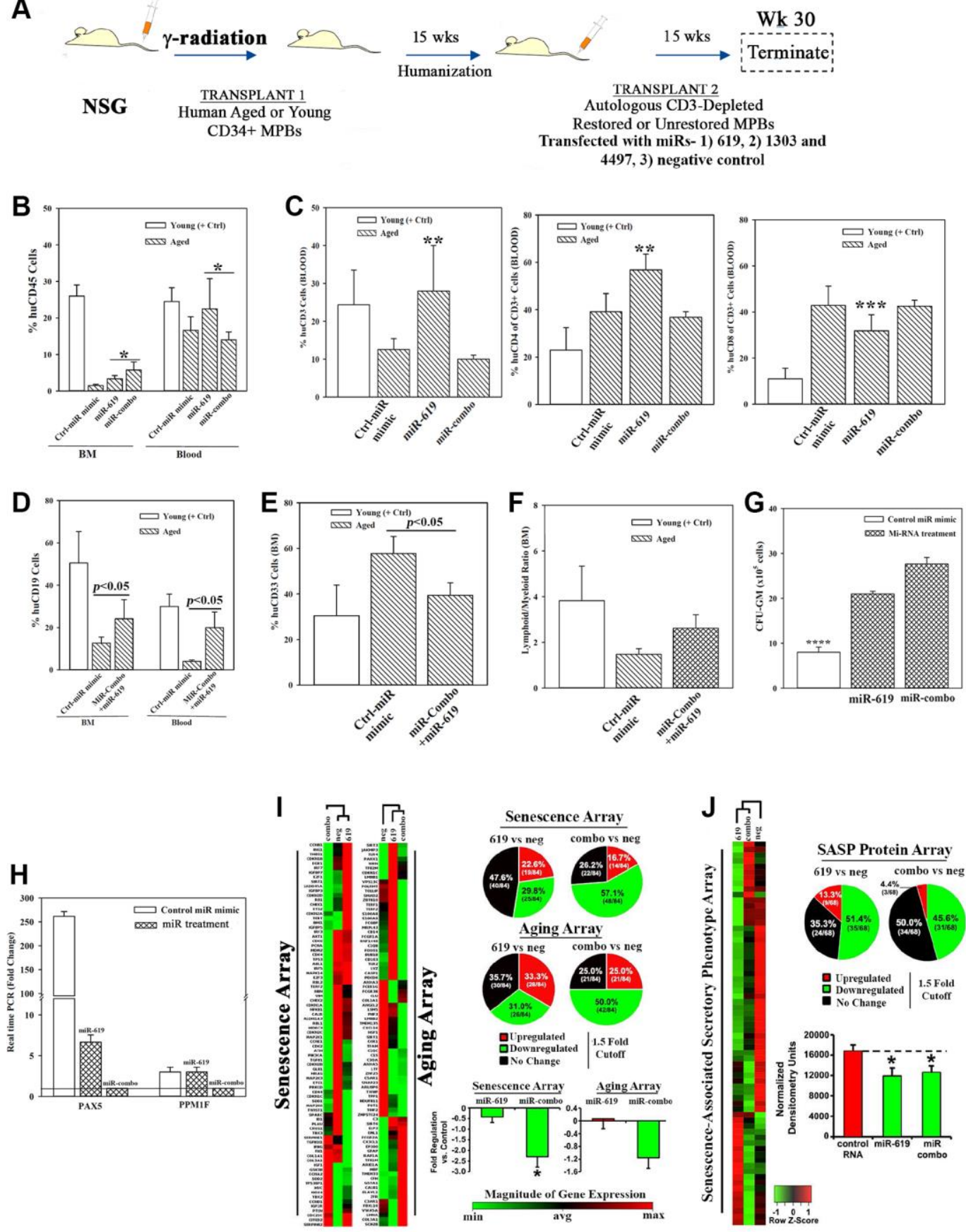

Figure 5. Hematopoietic restoration with miRNAs. (A) Restoration protocol with NSG was similar to Figure $2 \mathrm{H}$. Chimeric mice were given autologous CD3-depleted aged MPBs, transfected with miR-619, miR-combo, -619, -1303 and -4497, or control (RNA mimic) and then cultured for 7 days, $(n=18)$. (B-E) Mice were analyzed for huCD45 in BM and blood (B); huCD3, CD4 and CD8 in blood (C); HuCD19 in blood and BM (D); HuCD33 in BM (E). Results presented as \% mean cells \pm SD (F) Lymphoid:Myeloid ratio $\left(C D 3^{+}+C D 19^{+} / C D 33^{+}\right)$in $B M .(G)$ CFU-GM with huCD45+ cells from femurs, mean \pm SD. (H) qPCR for PAX5 and PPM1F with RNA from huCD45+cells from femurs. Fold change \pm SD used 1 for the lowest value. (I, J) RNA from ' $H$ ' were analyzed in qPCR human senescence and aging arrays. Normalized results used 1.5-fold cutoff to classify up- or down-regulation, or no change (I). SASF analyses with plasma. Semi-quantitative densitometry used 1.5fold cutoff, similar to I (J). Differential gene and protein expressions as heatmaps (left), pie charts (top) and bar graph (bottom), mean \pm SD. ${ }^{*} p \leq 0.05$ vs. control. See also Supplementary Figure 5. 


\section{DISCUSSION}

We report on functional improvement of the aged hematopoietic system, which occurred when the aged cells interacted with the secretome of young hematopoietic cells (UCB and MPBs). The restoration process improved cell senescence, lymphoid:myeloid ratio, inflammation, and NK numbers/function to enhance the innate immune compartment (Figure 6). The in vitro findings were successfully recapitulated in NSG mice carrying an aged human hematopoietic system. This was accomplished when we transplanted in vitro restored autologous aged MPBs or introducing aged MPBs transfected with restorative miRNAs. Thus, these findings open future translational studies to deliver the restorative miRs.

The evidence indicated long-term hematopoietic competence in mice as evidenced by the ability of
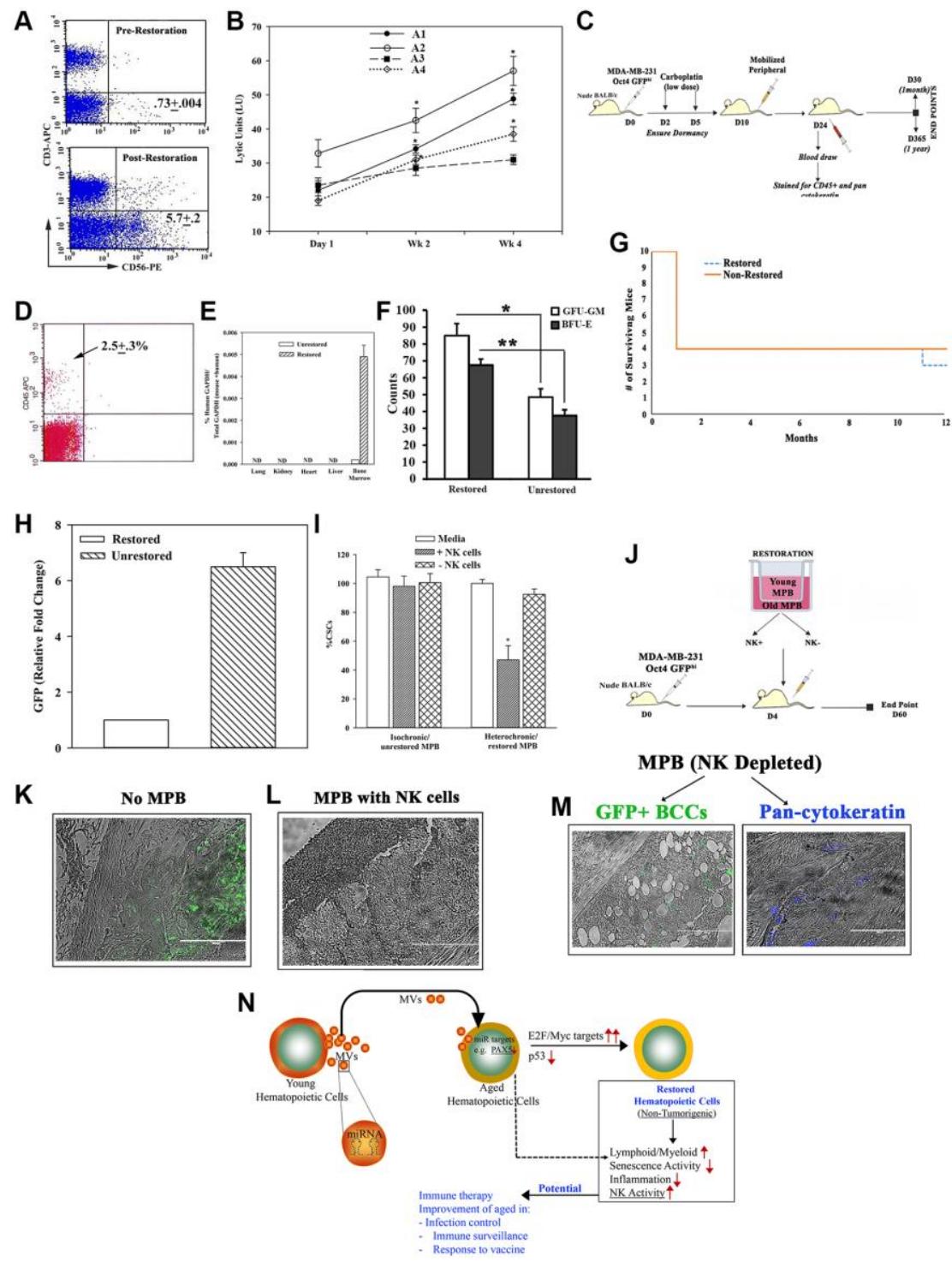

Figure 6. Restorative containing NK cell function. (A) Flow cytometry for CD56+ cells, pre- and post-restoration. (B) Timeline LUs (Supplementary Figure 6A for calculation) in restored cells. (C) Treatment protocol with mice harboring dormant CSCs. (D) Flow cytometry for huCD45+ cells in blood of mice after 1 month of injection with CD3-depleted restored cells. (E) qPCR for huGAPDH at 2 months after injection with CD3-depleted restored cells, mean \pm SD $(n=5)$; ND = not detected. (F) CFU-GM and BFU-E in BM at 1 month post-restoration, mean \pm SD, $n=5 .{ }^{*} p \leq 0.05$ vs. mice with unrestored cells. (G) Survival curve spanning the study period. (H) At yr 1 , qPCR for GFP with cells from femurs. The results presented as fold change in which the lowest value was assigned 1 , mean \pm SD, 4/group. (I) CSCs, co-cultured with restored MPBs (- or + NK cells) for $24 \mathrm{~h}$. \% CSCs (GFP+) were determined by microscopy and flow cytometry, mean \pm SD, $n=4$. (J) Protocol for NSG with dormant CSCs given restored CD3(-) MPB (-/+ NK cells). (K-M) GFP (surrogate of CSCs) in paraffin section of femurs, $-/+$ restored MPB: -MPB (K), +MPB (L), MPB without NK cells (M). (N) Summary: Aged hematopoietic cells instructed young cells to produce specific miRNA containing MVs to induce MYC and E2F targets to restore the aged MPBs, leading to increased NK activity. Transplantation of restored cells decreased hallmarks of aging: $\uparrow$ lymphoid:myeloid, $\downarrow$ senescence/inflammation. See also Supplementary Figure 6. 
CD34+ hematopoietic cells from the restored mice to reconstitute the hematopoietic system of naïve NSG (Figure 3A and 3B). Applying multiple methods, we concluded independence between the restorative process and MHC-II variation between donors (Supplementary Figure 1). More importantly, the released MVs did not express MHC-II (Supplementary Figure 1), indicating the future safety of MVs within the heterochronic cultures for clinical application such as hematopoietic and other tissue regeneration.

We noted increased cell survival of the aged MPBs when they are placed in the heterochronic cultures, which is consistent with enhanced function. It appears that cell restoration might be partly explained by partial reprograming, based on increased MYC pathways and decreased p53 [29]. Partial cellular reprogramming would imply dedifferentiation of hematopoietic cells into cells with stemness. We however argue against partial reprogramming since there was no evidence of malignancy in the mice subjected to long-term observation. A possible mechanism for the improved lymphoid:myeloid ratio in mice is based on other studies showing increased myeloid-associated genes in aged lymphoid cells [54]. Thus, it is possible that during restoration, the increased myeloid genes in lymphoid progenitors could revert to functionally young lymphoid cells.

Lymphoid CD19+ B-cells were increased in femurs and blood of mice when they were transplanted with restored cells, miR cultured or heterochronic cultures. Interestingly, there was less CD19+ cells in mice's spleen, indicating relatively reduced B-cells (Supplementary Figure 3). This was not in line with evidence of high activity in the prominent follicles of spleen. This led us to propose rapid exit of B-cells from the spleen during in vivo restoration to the peripheral circulation.

The miRNA cargo in MVs from heterochronic cultures were responsible for restoring the aged hematopoietic system. The aged cells are likely dictating the miR contents of the MVs within the heterochronic cultures. Prior to being placed in the heterochronic culture, the young (MPBs and UCB) cells exhibited distinct miRNA profiles (Figure 3). After exposure to aged MPBs, both types of young cells express similar miR profiles but distinct from their baseline contents. Thus, the results indicated that baseline young MVs would not be adequate to restore the hematopoietic system and such efficiency requires MVs from heterochronic cultures. Our ongoing studies indicated that we could accomplish in vivo hematopoietic restoration with MVs, purified from heterochronic cultures. Based on these studies, we deduced that the in vivo restoration was not the result of the injected in vitro restored cells but rather, their secretome. Indeed, we showed continued release of the restorative miRNA in the restored age MPBs (Supplementary Figure 4O). These findings warrant further studies to evaluate a treatment with the restorative miRNA directly into aged cells. Also, we were deliberate in transfecting with premiR because of the short life within the cells. The degradation of the premiR would indicate that the miRNA begins a chain of molecular interaction within the cells leading to restoration of the aged cells. These are exciting findings for us to examine other pathways for future treatment.

Age is generally associated with increases in the senescence program. Since plasma from huNSG showed a strong correlation between hematopoietic restoration and improved senescence, this suggested that in vivo restoration might have extended to the BM microenvironment and its non-hematopoietic components (Figures 2 and 5). The increase in NK numbers with restoration might have several functional benefits such as the elimination of senescence cells [36]. Thus, restoring HSC competence would lead to continued differentiation of functional NK cells to rapidly eliminate emerging senescence cells as they emerge in various organs. Going forward, we plan to combine a bar-coding system with single cell sequencing to understand restoration in real time and to track the various cell lineages. The data from protein and cDNA senescence arrays were confirmed by RNASeq, which showed decreases in inflammatory pathways and other aging hallmarks [55] (Figure 2). The noted decrease in PU.1/SP-1 would improve age-mediated inflammation [56].

Despite transplanting restored MPBs within a milieu of an aged human hematopoietic system, we observed hematopoietic competence that slightly surpassed mice transplanted with young CD34+ cells and significantly more than naïve mice given unrestored cells (Figure 2). This led us to surmise that the in vitro restored cells could be involved in regenerating the aged BM microenvironmental hematopoietic and nonhematopoietic supporting cells. Restoration-mediated decrease in PAX5 is consistent with reduced myeloid CFU-GM as well as its role in early B-cell and cellular development [34]. Since PAX5 and PPM1F are regulated by the restorative miR (Figures 5 and 6 ), it is important for future studies to dissect these pathways since this would provide insights into hematopoietic restoration.

Interestingly, the evidence indicated that the restored cells were behaving as the young cells because they were able to restore the aged MPBs (Supplementary Figure 4O). Thus, one can premise that MVs from the 
transplanted cells would continue to secrete MVs to impart in vivo restoration of the aged hematopoietic cells. If this was the sole method of in vivo restoration, then competent HSC function would not be explained by expansion during the in vitro restoration. Rather, the in vivo restoration was mediated by the transplanted cells, which showed experimental evidence of cells with young functions, indicated by omics and confirmatory functional studies. The LTC-IC assay, which is a surrogate of HSC function [38], showed sustained competence of the primitive hematopoietic cells during restoration, which contrasted mice transplanted with aged MPBs from isochronic cultures (Figure 1C).

Sequencing of restored cells identified MYC-linked targets as the only decreased pathways in aged cells, which was reversed with restoration (Figure 2B-2D). This was an intriguing observation since this increase correlated with decreased p53 pathways (Figures 1 and 2). Pharmacological inhibitors verified the roles for MYC and p53 in hematopoietic restoration (Figure 2G). Longterm observation of mice showed sustained health with no evidence of hematological malignancy, thereby arguing against full reprogramming as for induced pluripotent stem cells.

Increased E2F targets in the restored aged MPBs pointed to the involvement of cell cycle in the restoration process, particularly since $\mathrm{G} 1$ phase of the cell cycle occurs with silenced E2F activity (Figure 2) [57]. Indeed, our results indicated increases in cycling genes linked to E2F and MYC (Figure 2). MYC could also control E2F switch as a method to regulate the cell cycle of hematopoietic cells during restoration [57]. These findings are intriguing and support the basis for future studies to track the behavior of cells as they transition to restoration. RNA-Seq analyses indicated an increase in G2M pathway, which would facilitate the cells to undergo DNA repair during restoration. Although p53 was decreased during restoration, DNA repair was not compromised since there were increases in other repair genes (Figure 1J). Increased p53 in the aged cells is consistent with enhanced apoptosis identified in the omics study (Figure 2).

Similar CD34+/CD38- progenitors between young and aged MPBs could be explained by the highly proliferative state of aged HSCs $[8,58]$. The transplanted restored cells may have changed the BM niche to provide HSCs with a functional microenvironment thereby reducing the age-linked secretome, similar to occurrences in the aged intestinal system [59, 60].

Aging is associated with reduced clonal hematopoietic cell heterogeneity, providing an advantage to the emerging clones with mutated genes [12]. We have not determined if the restoration increased hematopoietic clonal diversity. We can extrapolate such benefit because of increased NK cells and HSC competence for long-term health benefit to the immune/ hematopoietic system. An interesting finding is an apparent role for PAX in aging. The aging population has decreased lymphoid cells, yet PAX was linked to the aged function. This suggested that PAX could be a negative regulator of lymphopoiesis, which might be negated by the restorative miRNA. Going forward, it is important to identify the targets of PAX using techniques such as global chromatin immune precipitation assays. As we identified the specific cell types needed to restore the aged hematopoietic system, our planned RNA-Seq will be able to determine what cell type express PAX.

The in vitro studies were efficient in determining a key role for MVs in the restoration processes. We also showed continued release of the restorative miRs in MVs from the restored aged cells. Hematopoietic restoration in NSG mice carrying an aged hematopoietic system was achieved when a second transplant occurred with miR-transfected aged MPBs. While MVs, along with the other transplanted hematopoietic cells, are expected to mediate the in vivo restoration, the mechanism could occur by MVs activating endogenous $\mathrm{BM}$ cells as well as the development of a network comprise of soluble and insoluble factors. The in vivo restoration was long-term, suggesting that the restoration may also involve the hematopoietic niche such as stromal cells. We are in the process of depleting different cell subsets in young MPBs to identify those involved in the restoration. Our pilot studies indicated that CD3 depletion enhanced the restoration and showed a need for accessory cells since CD34+ cells alone could not restore the aged cells. We are in the process of expanding on our depletion analyses and once we identified the causative cells, we will then begin to deplete subsets in the aged MPBs. After this, we will repeat the omics studies with the narrowed cell subsets and then knockdown $\geq 1$ of the identified miRs to determine if they are responsible for cell-mediated restoration.

Figure $6 \mathrm{~N}$ shows a summary of the main findings - MVs with specific miR cargo induce hematopoietic restoration, partly through increases in E2F/MYC and decreased p53 pathways. The restored hematopoietic system reverses its aging hallmarks, including increased NK activity. The summary figure shows the translational potential to the described findings, including the potential for enhancement of the immune system that is needed for vaccine response. The latter is particularly significant considering the current pandemic to facilitate responses of the aged to vaccine. The benefit to medicine is not 
limited to vaccine response but to improve the surveillance system to eliminate emerging malignancies, enhanced neural health and rapid response to infection.
Perhaps it would be prudent to determine how the present technology might be important to enhance the current immune therapies.

\section{MATERIALS AND METHODS}

\section{Key Resources Table}

\begin{tabular}{|c|c|c|}
\hline Reagent or Resource & Source & Identifier \\
\hline \multicolumn{3}{|l|}{ Antibodies } \\
\hline Anti-Human PTEN (WB) & Cell Signaling & Cat \#9559 \\
\hline Anti-Human AKT (WB) & Cell Signaling & Cat \#9272 \\
\hline Anti-Human phospho-GSK3 $\beta$ (WB) & Cell Signaling & Cat \#9336 \\
\hline Anti-Human CDK4 (WB) & Cell Signaling & Cat \#12790 \\
\hline Anti-Human Cyclin E (WB) & Cell Signaling & Cat \#4129 \\
\hline Anti-Human Cyclin D1 (WB) & Cell Signaling & Cat \#2978 \\
\hline Anti-Human Cyclin A (WB) & Santa Cruz & Cat \#sc-271682 \\
\hline Anti-Rabbit IgG-Rhodamine (FACS) & Santa Cruz & Cat \#sc-2367 \\
\hline Anti-Mouse IgG-PE (FACS) & Santa Cruz & Cat \#sc-3739 \\
\hline Anti-Human p53 (WB) & Abcam & Cat \#ab131442 \\
\hline Anti-Human Ki67 (IHC) & Abcam & Cat \#ab15580 \\
\hline Anti-Human Vinculin (WB) & Abcam & Cat \#ab91459 \\
\hline Anti-Human Fibronectin (WB) & Millipore-Sigma & Cat \#F3648 \\
\hline Anti-Human Pan Cytokeratin (IHC) & Millipore-Sigma & Cat \#C2562 \\
\hline Anti-Human $\beta$-actin (WB) & Millipore-Sigma & Cat \#A5441 \\
\hline Anti-Rabbit IgG-HRP (WB) & Thermo Fisher Scientific & Cat \#A16110 \\
\hline Anti-Mouse IgG-AlexaFluor 405 (IHC) & Thermo Fisher Scientific & Cat \#A-31553 \\
\hline Anti-Mouse IgG (FACS) & Thermo Fisher Scientific & Cat \#31160 \\
\hline PerCP-Cy5.5 Anti-Human CD45 (FACS) & BD Biosciences & Cat \#564105 \\
\hline FITC Anti-Human CD45 (FACS) & BD Biosciences & Cat \#555482 \\
\hline APC Anti-Human CD45 (FACS) & BD Biosciences & Cat \#555485 \\
\hline APC Anti-Human CD34 (FACS) & BD Biosciences & Cat \#555824 \\
\hline FITC Anti-Human CD38 (FACS) & BD Biosciences & Cat \#555459 \\
\hline APC Anti-Human CD3 (FACS) & BD Biosciences & Cat \#555335 \\
\hline PerCP-Cyanine5.5 Anti-Human CD3 (FACS) & BD Biosciences & Cat \#561557 \\
\hline PE Anti-Human FLA-DR (FACS) & BD Biosciences & Cat \#555812 \\
\hline PE Anti-Human CD56 (FACS) & BD Biosciences & Cat \#555516 \\
\hline PE Anti-Human CD4 (FACS) & BD Biosciences & Cat \#555347 \\
\hline APC Anti-Human CD33 (FACS) & BD Biosciences & Cat \#561817 \\
\hline APC Anti-Human CD8 (FACS) & BD Biosciences & Cat \#555369 \\
\hline PE Anti-Human CD19 (FACS) & BD Biosciences & Cat \#555413 \\
\hline PE Anti-Rabbit IgG (FACS) & BD Biosciences & Cat \#558553 \\
\hline Goat Anti-Rabbit IgG-AlexaFluor 405 (IHC) & ThermoFisher Scientific & Cat \#A-31556 \\
\hline Goat Anti-Rabbit IgG Rhodamine (IHC) & ThermoFisher Scientific & Cat \#31670 \\
\hline DAPI (IHC) & ThermoFisher Scientific & Cat \#D1306 \\
\hline $\operatorname{MitoSox}^{\mathrm{TM}}(\mathrm{IHC})$ & ThermoFisher Scientific & Cat \#M36008 \\
\hline \multicolumn{3}{|l|}{ Biological Samples } \\
\hline Human chronic myeloid leukemia bone morrow K562 cell & ATCC & Cat \#CCL-243 \\
\hline Human metastatic breast adenocarcinoma MDA-MB-231 cell & ATCC & Cat \#HTB-26 \\
\hline \multicolumn{3}{|l|}{ Chemicals, Peptides, and Recombinant Peptides } \\
\hline RPMI-1640 & Millipore Sigma & Cat \#R0883 \\
\hline DMEM with high glucose & Millipore Sigma & Cat \#D5796 \\
\hline L-Glutamine & Millipore Sigma & Cat \#G8540 \\
\hline Penicillin-Streptomycin & Millipore-Sigma & Cat \#P0781 \\
\hline$\beta$-mercaptoethanol & Millipore-Sigma & Cat \#444203 \\
\hline Hank's Balanced Salt Solution with Calcium and Magnesium & Millipore-Sigma & Cat \#55037C \\
\hline Fetal Calf Serum & Millipore-Sigma & Cat \#F2442 \\
\hline
\end{tabular}


DNase I

Ficoll Hypaque

HLM006474

BCI-137

Dimethyl Sulfoxide

Sodium Chloride

Magnesium Chloride

Glycerol

NP-40

Phosphate-Buffered Saline

Tween 20

Triton-X 100

Protease Inhibitor

Phosphatase Inhibitor

CarboxyFluorescein Succinimidyl Ester

Sybr Green PCR Master Mix II

Tris- $\mathrm{HCl}$

Exosome-depleted FBS Media Supplement

Recombinant Human GM-CSF

IL-3

Erythropoietin

JQ1

CellTracker Blue CMAC Dye

Idasanutlin
Bovine Serum Albumin

$\begin{array}{ll}\text { Millipore-Sigma } & \text { Cat \#69182 } \\ \text { Millipore-Sigma } & \text { Cat \#H8889 } \\ \text { Millipore Sigma } & \text { Cat \#324461 } \\ \text { Millipore Sigma } & \text { Cat \#531552 } \\ \text { Fisher Scientific } & \text { Cat \#BP231-100 } \\ \text { Millipore Sigma } & \text { Cat \#S9888 } \\ \text { Millipore Sigma } & \text { Cat \#63036 } \\ \text { Millipore Sigma } & \text { Cat \#356352 } \\ \text { Millipore Sigma } & \text { Cat \#492016 } \\ \text { Millipore Sigma } & \text { Cat \#D1408 } \\ \text { Millipore Sigma } & \text { Cat \#9005-64-5 } \\ \text { Millipore Sigma } & \text { Cat \#T8787 } \\ \text { Millipore Sigma } & \text { Cat \#A3912 } \\ \text { Millipore Sigma } & \text { Cat \#5056489001 } \\ \text { Millipore Sigma } & \text { Cat \#P5726 } \\ \text { ThermoFisher Scientific } & \text { Cat \#46410 } \\ \text { ThermoFisher Scientific } & \text { Cat \#4309155 } \\ \text { Fisher Scientific } & \text { Cat \#BP153 } \\ \text { System Biosciences } & \text { Cat \#EXO-FBS-250A-1 } \\ \text { R\&D Systems } & \text { Cat \#215-GM } \\ \text { R\&D Systems } & \text { Cat \#203-IL } \\ \text { R\&D Systems } & \text { Cat \#287-TC } \\ \text { Medchemexpress } & \text { Cat \#HY-13030 } \\ \text { ThermoFisher Scientific } & \text { Cat \#C2110 } \\ \text { MedKoo Biosciences } & \text { Cat \#205917 }\end{array}$

Critical Commercial Assays

Total Exosome Isolation Reagent

Exosome-Human CD63 Isolation/Detection Reagent

SuperSignal $^{\mathrm{TM}}$ West Femto Maximum Sensitivity Substrate

CD34 microbead, human kit

CD56 microbead, human kit

Mouse Cell Depletion Kit

RNeasy Mini Kit

Human Aging RT² Profiler PCR Array

HiPerfect Reagent

miRCURY RNA Isolation Kit

NEBNext ${ }^{\circledR}$ Poly(A) mRNA Magnetic Isolation Module

Amaxa P3 Primary Cell 4D-Nucleofector X Kit

7-AAD/CFSE Cell-Mediated Cytotoxicity Assay Kit

CellTiter-Blue ${ }^{\circledR}$ Cell Viability Assay

Experimental Models: Organisms/Strains

NSG Mice

BALBc Mice

Oligonucleotides

Primer: GAPDH, Human Forward:

CAGAAGACTGTGGATGGCC

Primer: GAPDH, Human Reverse:

CCACCTTCTTGATGTCATC

Primer: GAPDH, Human and Mouse Forward:

AGTCCCCCACCACACCACTGAAT

Primer: GAPDH, Human and Mouse Reverse:

TTGATGGTACATGACAAGGTGC

Primer: CASP14 Forward: GTTCCGAAGAAGACCTGGAT

Primer: CASP14 Reverse: TTCTCCAGCTTGACCATCTC

Primer: GALNT6 Forward: GGAGCACCTAAAGGAGAAGC

Primer: GALNT6 Reverse: CTGTCTTGTCCTCAGCGATT

Primer: PAX5 Forward: CATCCGGACAAAAGTACAGC

Primer: PAX5 Reverse: ACCGGAGACTCCTGAATACC

$\begin{array}{ll}\text { ThermoFisher Scientific } & \text { Cat \#4478359 } \\ \text { ThermoFisher Scientific } & \text { Cat \#10606D } \\ \text { ThermoFisher Scientific } & \text { Cat \#34094 } \\ \text { Miltenyi Biotec } & \text { Cat \#130-046-703 } \\ \text { Miltenyi Biotec } & \text { Cat \# 130-050-401 } \\ \text { Miltenyi Biotec } & \text { Cat \#130-090-858 } \\ \text { Qiagen } & \text { Cat \#74104 } \\ \text { Qiagen } & \text { Cat \# 330231 } \\ \text { Qiagen } & \text { Cat \# 301705 } \\ \text { Exiqon } & \text { Cat \# 300112 } \\ \text { New England BioLabs } & \text { Cat \# E7490L } \\ \text { Lonza } & \text { Cat \# V4XP-3024 } \\ \text { Cayman Chemical } & \text { Cat \# 600120 } \\ \text { Promega } & \text { Cat \#G8080 }\end{array}$

The Jackson Laboratory Cat \#5557

The Jackson Laboratory Cat \#000651

$\begin{array}{ll}\text { Life Technologies } & \text { N/A } \\ \text { Life Technologies } & \text { N/A } \\ \text { Life Technologies } & \text { N/A } \\ \text { Life Technologies } & \text { N/A } \\ \text { This Paper } & \text { N/A } \\ \text { This Paper } & \text { N/A } \\ \text { This Paper } & \text { N/A } \\ \text { This Paper } & \text { N/A } \\ \text { This Paper } & \text { N/A } \\ \text { This Paper } & \text { N/A }\end{array}$




\begin{tabular}{|c|c|c|}
\hline Primer: PPM1F Forward: CTTGTCTGACCCTGTGAACC & This Paper & N/A \\
\hline Primer: PPM1F Reverse: CTTGGCTTTCCTGAGAAACA & This Paper & N/A \\
\hline Primer: SUMO2 Forward: ATGGTTCTGTGGTGCAGTTT & This Paper & N/A \\
\hline Primer: SUMO2 Reverse: CTGCTGTTGGAACACATCAA & This Paper & N/A \\
\hline Primer: $\beta$-actin Forward: ATCCTCACCCTGAAGTACCC & This Paper & N/A \\
\hline Primer: $\beta$-actin Reverse: AGCCTGGATAGCAACGTACA & This Paper & N/A \\
\hline \multicolumn{3}{|l|}{ Software and Algorithms } \\
\hline RNA-protein Association and Interaction Networks v1.0 & Junge et al., 2017 & https://rth.dk/resources/rain/ \\
\hline Partek $^{\circledR}$ Genomics Suite ${ }^{\circledR}$ software v7.0 & Partek Inc., 2018 & https://www.partek.com/ \\
\hline STRING, v11.0 & Szklarczyk D et al., 2019 & https://string-db.org/ \\
\hline CLC Genomics Workbench, v11.0 & Qiagen & N/A \\
\hline TargetScan v7.0 & Agarwal et al., 2015 & http://www.targetscan.org/ \\
\hline TarBase v8.0 & Karagkouni et al., 2018 & $\underline{\text { http://diana.imis.athena- }}$ \\
\hline BD CellQuest Pro $^{\mathrm{TM}}$ & BD Biosciences & N/A \\
\hline UN-SCAN-IT Gel ${ }^{\mathrm{TM}}$ & Silk Scientific, Inc. & $\begin{array}{l}\text { https://www.silkscientific.c } \\
\text { om/index.htm }\end{array}$ \\
\hline FlowJo & BD Biosciences & $\begin{array}{l}\text { https://www.flowjo.com/sol } \\
\underline{\text { utions/flowjoRRID:SCR_00 }} \\
\underline{8520}\end{array}$ \\
\hline Adobe Photoshop & Adobe & $\begin{array}{l}\text { https://www.adobe.com/pro } \\
\text { ducts/photoshop.htmlRRID: } \\
\underline{\text { SCR_014199 }}\end{array}$ \\
\hline BCL2FASTQ & Illumina & $\begin{array}{l}\text { https://support.illumina.com } \\
\text { /sequencing/sequencing sof } \\
\underline{\text { tware/bcl2fastq-conversion- }} \\
\underline{\text { software.htmlRRID:SCR_0 }} \\
\underline{15058}\end{array}$ \\
\hline $\mathrm{RT}^{2}$ Profiler PCR Array Human Senescence & NCBI Genome Expression Omnibus & GSE141838 \\
\hline $\mathrm{RT}^{2}$ Profiler PCR Array Human Aging & NCBI Genome Expression Omnibus & GSE141837 \\
\hline RNA sequencing & NCBI Genome Expression Omnibus & GSE138563 \\
\hline miRNA sequencing & NCBI Genome Expression Omnibus & GSE138564 \\
\hline \multicolumn{3}{|l|}{ Other } \\
\hline Evos Fl Auto 2 & Thermo Fisher Scientific & AMAFD2000 \\
\hline 7300 Real Time PCR System & Thermo Fisher Scientific & 7300 \\
\hline Qubit Instrument & Thermo Fisher Scientific & Q33226 \\
\hline Tapestation 2200 Instrument & Agilent & G2965A \\
\hline D1000 Screentapes & Agilent & $5067-5582$ \\
\hline Illumina's Nextseq 500 & Illumina & Serial \# NB500952 \\
\hline Synergy HTX-Multi-Mode Reader & Biotek & Synergy HTX \\
\hline FACS Calibur & BD Biosciences & E4400 \\
\hline
\end{tabular}

\section{Cell lines}

K562 and MDA-MB-231 were cultured as per American Type Culture Collection instruction. The cell lines were tested by Genetica DNA Laboratories (Burlington, NC) and were deemed to be the original cells using ATCC STR database (https://www.atcc.org/search-str-database).

\section{Human subjects}

The use of de-identified human mobilized peripheral blood (MPB), peripheral blood (PB) and umbilical cord blood (UCB) was approved by Rutgers Institutional Review Board (IRB), Newark, NJ, USA.

\section{MPB}

MPB was collected from aged ( $>60$ yrs) and young (<30 yrs) donors (Supplementary Table 1). Aliquots (10-20 mL) of MPB for A5-A8 (aged) and Y6-Y8 (young) were donated for research purposes through Progenitor Cell Therapy (Allendale, NJ, USA). Donors A1-A4 (aged) and Y1-Y5 (young) were recruited, mobilized and subjected to leukapheresis by HemaCare Corporation (Van Nuys, CA, USA). HemaCare was approved as a collection site by Rutgers IRB. The site is FDA-registered, AABB-accredited and operated under GMP-compliance. Study participants were given subcutaneous Neupogen ${ }^{\circledR}$ (G-CSF) at $5 \mu \mathrm{g} / \mathrm{kg} /$ day for 5 days. On day 6, MPB was collected using the Spectra Optia ${ }^{\circledR}$ Apheresis System to process $18 \mathrm{~L}$ of blood at a 
flow rate of 50 to $100 \mathrm{~mL}$ per min. Immediately after mobilization, the MPB were shipped to Rutgers.

\section{Umbilical cord blood (UCB)}

The demographics obtained for 10 UCB samples are shown in Supplementary Table 1. The samples were provided within $24 \mathrm{~h}$ of collection by the Community Blood Services (Montvale, NJ, USA), which is an AABBaccredited blood bank registered with the FDA. The mononuclear fraction was isolated by Ficoll-Hypaque density gradient and then cryopreserved for later use.

\section{Peripheral blood (PB)}

PB was obtained from healthy donors (18-30 yrs) and the mononuclear fraction isolated by Ficoll Hypaque density gradient.

\section{Isolation of $\mathrm{CD34}^{+}$cells and cell cryopreservation}

Total MPB, herein referenced as total nucleated cells (TNC), were cryopreserved by adding chilled cryopreservation media to the cell suspension at a 1:1 ratio while gently shaking the cells. The resuspended TNC was $\sim 5 \times 10^{7}$ cells $/ \mathrm{mL}$. Cells were stored using a controlled rate freezer (Cryo Met Freezer, Thermo Fisher) at $-1{ }^{\circ} \mathrm{C} / \mathrm{min}$ until the temperature reached $100^{\circ} \mathrm{C}$. After this, the cells were transferred into liquid nitrogen.

CD34 ${ }^{+}$cells were selected using the CD34 microbead human kit (Miltenyi, Auburn, CA, USA). The method followed manufacturer's instructions. Briefly, TNC was pelleted at $4^{\circ} \mathrm{C}, 10 \mathrm{~min}, 500 \mathrm{~g}$. The TNCs were resuspended in cold MACS buffer at a concentration of $10^{8}$ cells $/ 300 \mu \mathrm{L}$ buffer. Cell suspension was incubated in $100 \mu \mathrm{L}$ of FcR Blocking Reagent and CD34 MicroBeads for $30 \mathrm{~min}$ at $4^{\circ} \mathrm{C}$. After this, cells were washed with MACS buffer and the $\mathrm{CD} 34^{+}$cells were positively selected by magnetic separation with LS columns. The purified $\mathrm{CD} 34^{+}$cells were immediately cryopreserved as described above.

\section{Transwell assay}

Non-contact cultures were performed in 6- or 12-well transwell system, separated by a $0.4 \mu$ membrane (BD Falcon, ThermoFisher). In the case of 6-well plates, the inner wells contained $10^{7}$ young MPB or CB with the same number of aged MPBs in the outer wells. The numbers were scaled lower for 12-well plates. At optimization, cells were cultured for up to 5 wks in RPMI 1640 supplemented with $10 \%$ FCS, $2 \mathrm{mM}$ glutamine and $0.5 \mu \mathrm{M} \beta$-mercaptoethanol ( $\beta$-ME) (R10 media). Cultures with allogeneic cells were designated heterochronic and those with autologous cells, isochronic. During the culture period, $50 \%$ percent of cell-free media were replaced every four days with fresh R10 media without cell passaging. Except for FCS, we did not supplement the media until we were ready to evaluate aged hematopoietic activity in clonogenic assay. The latter contained supplement (see below for method). In this case, we did not mask the restoration with exogenous growth factors. Based on the optimization data, all other transwell cultures were conducted for $1 \mathrm{wk}$.

\section{Cell migration from inner to outer wells}

Transfer of cells from the inner to the outer wells of co-cultures were studied as follows: young MPBs were labeled with CarboxyFluorescein succinimidyl ester (CFSE) (Thermo Fisher) following manufacturer's recommended protocol. Briefly, CFSE was diluted in $1 \mathrm{x}$ PBS to $5 \mu \mathrm{M}$ (stock solution) and then diluted at $1 / 1000$ (working solution). The latter was used to label cells by incubating for $20 \mathrm{~min}$ at room temperature. The labeled cells were added to the inner wells of the heterochronic cultures and at weekly intervals, the cells in the outer wells were analyzed for CFSE by flow cytometry.

\section{Flow cytometry}

Cells $\left(10^{6}\right)$ were labeled with the primary antibodies in $100 \mu \mathrm{l}$ PBS. Each labeling used an isotype IgGs for background labeling (control) at the same concentration as the primary antibodies (see above for concentrations). After 30 mins at room temperature, the cells were washed with PBS and acquired on a FACSCalibur flow cytometer (BD Biosciences). Data were analyzed using BD CellQuest Pro ${ }^{\mathrm{TM}}$ software (BD Biosciences).

\section{Western blot analyses}

Cell extracts were isolated with cell lysis buffer (50 mM Tris- $\mathrm{HCl}(\mathrm{pH} 7.4), 100 \mathrm{mM} \mathrm{NaCl}, 2 \mathrm{mM}$ $\mathrm{MgCl}_{2}, 10 \%$ glycerol, and $\left.1 \% \mathrm{NP}-40\right)$ as described (Ghazaryan et al., 2014). Extracts (15 $\mu$ g protein) were electrophoresed on SDS-PAGE and then transferred to polyvinylidene difluoride membranes (Perkin Elmer). The membranes were incubated overnight at $4{ }^{\circ} \mathrm{C}$ on rocker with primary antibodies in $5 \%$ milk dissolved in $1 x$ PBS tween. Next day, the membranes were incubated with species-specific HRP tagged secondary $\mathrm{IgG}$ in the same diluent. After $2 \mathrm{~h}$, the membranes were developed by chemiluminescence using SuperSignal West Femto Maximum Sensitivity Substrate (Thermo Fisher Scientific).

\section{Clonogenic assays}

Clonogenic assays for hematopoietic progenitors, granulocytic-monocytic (CFU-GM) and early erythroid 
(BFU-E), were performed as described in methylcellulose matrices (Rameshwar et al., 2001). Cultures for CFU-GM contained $3 \mathrm{U} / \mathrm{mL}$ GM-CSF and BFU-E, $3 \mathrm{U} / \mathrm{mL}$ rhIL-3 and $2 \mathrm{U} / \mathrm{mL}$ Epo. Colonies were counted by a blinded observer. Each colony contained $>15$ cells.

\section{Modified long-term culture-initiating cell (LTC-IC) assay}

Confluent stromal cells in the outer well of the transwell cultures were subjected to $1.5 \mathrm{~Gy}$, delivered by a cesium source. After $16 \mathrm{~h}$, the floating cells were washed and $10^{7} \mathrm{BM}$ mononuclear cells added to the $\gamma$-irradiated stroma. At wks 6, 10 and 12, aliquots of mononuclear cells were assayed for CFU-GM in clonogenic assays (see above) [61].

\section{Mixed lymphocyte reaction (MLR)}

One-way mixed lymphocyte reaction (MLR) was performed as described previously [62]. Briefly, $\gamma$ irradiated (20 Gy) stimulator cells from isochronic or heterochronic cultures were added to 96 well-flat bottom plates (Corning, Corning, NY) at $10^{6} / \mathrm{mL}$ in $0.1 \mathrm{~mL}$ volume in triplicates. Autologous responder freshly thawed cells were added at the same concentration and volume. Control MLR used peripheral blood mononuclear cells (PBMCs) from two different donors (20-30 yrs). The MLR reactions were incubated at $37^{\circ} \mathrm{C}$. At $72 \mathrm{~h}$, the wells were pulsed with $1 \mu \mathrm{Ci} /$ well of [methyl- ${ }^{3} \mathrm{H}$ ]TdR (70-90 Ci/mmol; NEN Radiochemicals, PerkinElmer, Akron, OH). After $16 \mathrm{~h}$, the cells were harvested with a $\mathrm{PhD}$ cell harvester (Cambridge Technologies, Bedford, MA) onto glass-fiber filters, and $\left[{ }^{3} \mathrm{H}\right] \mathrm{TdR}$ incorporation quantified in a scintillation counter (Beckman Coulter, Brea, CA, USA). The results are expressed as the stimulation index (S.I.), which is the mean dpm of experimental cultures (responders + gamma-irradiated stimulators)/dpm of responder cells cultured in media alone.

\section{Cell titer blue viability assay}

The cells in the outer wells of transwell cultures were assayed for viability with CellTiter-Blue Cell Viability Assay kit (Promega, Madison, WI). Viability analyses followed manufacturer's instructions. Briefly, CellTiterBlue reagent was added to aliquots of cells in 96-well plates. The plates were incubated for $4 \mathrm{~h}$ at $37^{\circ} \mathrm{C}$ and then read on a fluorescence microplate reader at $560 \mathrm{~nm}$ excitation $/ 590 \mathrm{~nm}$ emission. Percent viability was calculated from a reference using untreated healthy cells, which were considered $100 \%$ viable, and cell-free wells containing reagent alone, which were considered $0 \%$ viable.

\section{Real time PCR for human cells in mouse femur}

RNA extraction was performed according to manufacturer's protocols with the RNeasy Mini Kit (Qiagen, Germantown, MD). Quality and concentration of RNA were determined with the Nanodrop ND-1000 spectrophotometer (ThermoFisher Scientific). The High-Capacity cDNA Reverse Transcription Kit (Life Technologies) was used to convert RNA to cDNA and $10 \mathrm{ng}$ used in real-time PCR with Sybr Green PCR Master Mix II (Life Technologies) using primers from human and mouse GAPDH (see above).

\section{PCR array}

Total RNA $(2 \mu \mathrm{g})$ was extracted from MPB with the RNeasy Mini Kit (Qiagen) and then reverse-transcribed using the First Strand cDNA Synthesis Kit (Life Technologies). The cDNA (200 ng) was used for quantitative PCR with the Human Cellular Senescence $\mathrm{RT}^{2}$ Profiler $^{\mathrm{TM}}$ PCR Array (Qiagen) containing 84 key genes involved in the initiation and progression of the biological process causing cells to lose the ability to divide. Prepared cDNA templates were added to the ready-to-use PCR master mix at equal volumes within each well of the same plate. The arrays were then run on the 7500 Real Time PCR System (Life Technologies) with the cycling profile ( 40 cycles) as follows: $94^{\circ} \mathrm{C}$ for 15 secs and $60^{\circ} \mathrm{C}$ for $45 \mathrm{secs}$. The data were analyzed with Qiagen PCR Array Data Analysis Software and normalized to five housekeeping genes provided within each array. Controls were also included for genomic DNA contamination, RNA quality, and general PCR performance. The normalized data are presented as fold difference, with a value of 1 representing no change. Differential and overlapping miRNAs are presented in Venn diagram. The overlapping areas include miRNAs with $<1.5$-fold difference among groups.

\section{MV isolation and nanoparticle tracking analysis}

MVs were isolated from cell culture media as described (Bliss et al., 2016). In addition, MVs were also isolated with the Total Exosome Isolation Kit (Life Technologies), using a modified version of the manufacturer's protocol. Specifically, isochronic and heterochronic cultures were established with Exosome-depleted FBS Media Supplement (System Biosciences, Palo Alto, CA, USA). Culture media collected on the 4th and 7th days were pelleted and supernatant transferred to another tube for further clarification at $2000 \mathrm{~g}$ for $30 \mathrm{~min}$ to remove residual cells and debris. The remaining supernatant was transferred to a fresh tube and 0.5 volumes of Total MV Isolation reagent was added for overnight incubation at $4^{\circ} \mathrm{C}$. The following day, samples were 
centrifuged at $10,000 \mathrm{~g}$ for $1 \mathrm{~h}$ at $4{ }^{\circ} \mathrm{C}$ to pellet the exosomes for subsequent nanoparticle tracking analysis (NTA) or long-term storage at $-80^{\circ} \mathrm{C}$. Analysis of absolute size distribution of MVs was performed using the NanoSight LM10 with NTA3.1 software (Malvern Panalytical, Malvern, UK). Particles were automatically tracked and sized based on Brownian motion and the diffusion coefficient. For NTA, MVs were re-suspended in $0.5 \mathrm{~mL}$ of PBS and measured using the following parameters: Temperature $=25.6+/-0.5^{\circ} \mathrm{C}$; Viscosity $=$ (Water) $0.99+/-0.01$ $\mathrm{cP}$; Measurement time $=30 \mathrm{sec}$; Syringe pump speed $=$ 30. The detection threshold was similar in all samples. Three recordings were performed for each sample.

\section{MV entry into aged cells}

Purified MVs $\left(4 \times 10^{6} / 500 \mu \mathrm{L}\right)$ from 3-day co-cultures were resuspended in PBS containing $25 \mu \mathrm{M}$ CellTracker Blue CMAC Dye (ThermoFisher Scientific). The MVs were incubated for $45 \mathrm{~min}$ at $37^{\circ} \mathrm{C}$. After this, MVs were washed as follows: Increased PBS to $5 \mathrm{~mL}$ followed by ultracentrifugation at $130,000 \mathrm{xg}$ for 80 mins in the cold. The MVs were then added to naïve aged MPBs and then subject to timeline ( 24 and $48 \mathrm{~h}$ ) for cellular uptake. The latter was assessed by the following methods: Confocal 3D imaging using Olympus Fluoview FV10i and the images processed with the FV10-ASW software, Version 04.02.03.06; 2D imaging with the EVOS FL Auto2 (Invitrogen/ThermoFisher Scientific).

\section{MitoSox assay}

MPB cells $\left(10^{6}\right)$ were labeled with anti-CD34-APC and -CD45-PerCp-Cy5.5, as described below for flow cytometry. The cells were washed and incubated with $5 \mu \mathrm{M}$ MitoSox ${ }^{\mathrm{TM}}$ Red for $10 \mathrm{~min}$ at $37^{\circ} \mathrm{C}$ in the dark and then washed again with warm HBSS. The data was acquired and analyzed with the FACSCalibur.

\section{Senescence Associated Secretory Phenotype (SASP) array}

\section{Media}

Senescence associated secretory factors (SASFs) in media from heterochronic cultures at day 1 and wk 4 were analyzed with Custom C-Series Human Antibody Arrays with 68 different factors linked to cellular senescence [63]. The antibodies were obtained from Ray Biotech (Norcross, GA, USA). Briefly, cell culture media were pelleted at low speed centrifugation $(300 \mathrm{~g})$ to remove cell debris and stored in siliconized microfuge tubes at $-80^{\circ} \mathrm{C}$ until assayed. Incubation and detection of factors within the conditioned media followed the manufacturer's suggested protocol.
Background levels were calculated by incubating the arrays with complete media alone and then subtracting the obtained values from each conditioned media experiment. Densitometry was performed using the UN-SCAN-IT densitometry software (Silk Scientific; Orem, UT).

\section{Plasma}

Detection of SASFs in plasma of huNSG mice was performed as described above for media. Briefly, blood from huNSG mice was pelleted for $10 \mathrm{~min}$ at $300 \mathrm{~g}$ and the plasma supernatant collected in siliconized microfuge tubes for SASF determination. Background was subtracted from the density of parallel analyses with plasma from non-humanized NSG mice.

\section{Senescence and aging gene arrays}

Cells were flushed from the femurs of huNSG using a 26-gauge needle. Murine cells were eliminated with a Mouse Cell Depletion Kit. Total RNA $(2 \mu \mathrm{g})$ was extracted from purified cells using the RNeasy Mini Kit and reverse-transcribed with the $\mathrm{RT}^{2}$ First Strand Kit. $20 \mathrm{ng}$ of cDNA was used for qPCR with the Human Cellular Senescence and Human Aging RT ${ }^{2}$ Profiler ${ }^{\mathrm{TM}}$ PCR Arrays (Qiagen). Arrays were run on the 7300 Real Time PCR System (Life Technologies) with the cycling profile ( 40 cycles): $94^{\circ} \mathrm{C}$ for 15 secs and $60^{\circ} \mathrm{C}$ for 45 secs. Gene expression analysis was performed using Qiagen PCR Array Data Analysis Software. The data were normalized to five housekeeping genes provided within each array. The data was submitted to the NCBI Genome Expression Omnibus (GEO; https://www.ncbi.nlm.nih.gov/geo/) under SuperSeries accession number GSE138565. Hierarchical clustering and heat map generation were performed with Heatmapper software (http://www.heatmapper.ca/), as described [64].

\section{MiRNA microarray and qPCR}

Total RNA (500 ng) was isolated from MVs using the miRCURY RNA Isolation Kit (Exiqon). RNA was reverse-transcribed with the miScript II RT Kit (Qiagen) and $20 \mathrm{ng}$ of cDNA used for qPCR with the human miFinder miRNA Array (Qiagen). The PCR was done with the following cycling conditions: $94^{\circ} \mathrm{C}$ for 15 mins, 40 cycles at $94^{\circ} \mathrm{C}$ for $10 \mathrm{secs}, 55^{\circ} \mathrm{C}$ for 30 secs, $70^{\circ} \mathrm{C}$ for 30 secs, followed by melt curve analysis. The data were analyzed with the online miScript miRNA PCR Array data analysis tool (Qiagen).

Validation of miRNAs identified in the microarray and NGS was done by individual qPCR experiments using miScript primer assays and similar cycling and analysis 
schemes. Total RNA $(2 \mu \mathrm{g})$ was also isolated from cells, as described above, for profiling of downstream miRNA targets by qPCR using the primer pairs listed above with the following cycling conditions: $95^{\circ} \mathrm{C}$ for 15 mins, 40 cycles at $94^{\circ} \mathrm{C}$ for $15 \mathrm{secs}, 51^{\circ} \mathrm{C}$ for $30 \mathrm{secs}$, $72^{\circ} \mathrm{C}$ for $30 \mathrm{secs}$, followed by melt curve analysis. Analyses were performed with Qiagen PCR Array Data Analysis Software, as described above. Array and individual qPCR studies were normalized to RNU6, SNORD68 and SNORD95 and presented as fold change. The 30 genes with marked changes following restoration were selected for links to other genes using RNA-Protein Association and Interaction Networks (RAIN) [65].

\section{RNA-Seq}

RNA Seq was performed at the Genomics Center at Rutgers New Jersey Medical School (Newark, NJ, USA). Total RNA was submitted to the center where poly A RNA was purified using NEBNext ${ }^{\circledR}$ Poly(A) mRNA Magnetic Isolation Module (New England BioLabs, Ipswich, MA, USA). Next generation sequencing (NGS) libraries were prepared using the NEB Ultra II Library Preparation Kit and NEBNext ${ }^{\circledR}$ Multiplex Oligos for Illumina (Dual Index Primers Set 1) (New England BioLabs). The generation of the libraries followed manufacturer's protocol. The libraries were subjected to quality control using Qubit instrument and high sensitivity Kit from Thermo Fisher as well as Tapestation 2200 instrument and D1000 ScreenTapes from Agilent (Santa Clara, CA, USA). The libraries were diluted to $2 \mathrm{nM}$ and then denatured as per Illumina's protocol and run on Illumina's NextSeq instrument (San Diego, CA, USA) using 1X75 cycle high throughput kit. The BCL files that were generated from the sequencing were demultiplexed and converted to FastQ files using BCL2FASTQ software from Illumina. All raw and processed sequencing data have been submitted to the NCBI Genome Expression Omnibus (GEO; https://www.ncbi.nlm.nih.gov/geo/) under accession number GSE138563, SuperSeries accession number GSE138565.

\section{MiRNA sequencing (miR Seq)}

Total RNA from MVs and cells was isolated using the miRCURY RNA Isolation Kit with small and large RNAs fractionated with the RNeasy MinElute Cleanup Kit, both according to manufacturer's recommended specifications (Qiagen). Half of the small RNA fraction (200 ng) was used in library preparation with the NEBNext Multiplex Small RNA Sample Prep Set for Illumina - Set 1 (New England Biotechnology), according to the following protocol: (1) ligation of the 3' SR Adaptor, (2) hybridization of the reverse transcription primer, (3) ligation of the 5' SR Adaptor, (4) reverse transcription for first strand cDNA synthesis and (5) PCR enrichment. After PCR, samples were cleaned up and size selection performed. Briefly, $2 \mu \mathrm{l}$ of sample was subjected to TapeStation (Agilent) analysis to ascertain band sizes. Samples were run on $8 \%$ acrylamide gel at $100 \mathrm{~V}$ for $1 \mathrm{hr}$, with correct size bands excised for gel purification. Small RNA libraries were diluted to $2 \mathrm{nM}$ and run on a miSeq System (Illumina) for NGS using the V2 kit (Illumina). All raw and processed sequencing data have been submitted to the NCBI Genome Expression Omnibus (GEO; https://www.ncbi.nlm.nih.gov/geo/) under accession number GSE138564, SuperSeries accession number GSE138565.

\section{Data analyses}

\section{RNA network}

Specific genes from the senescence array data were analyzed for RNA interaction using the RNA-protein Association and Interaction Networks (v1.0) (RAIN) [65]. The upregulated genes following restoration were input into the program. The database projected the output in the form of networks and co-expression graphs.

\section{RNA Seq}

Partek $^{\circledR}$ Flow $^{\circledR}$ software was used to align the reads to Homo Sapiens assembly hg38. Transcript abundance of the aligned reads were performed with Partek's (version 7) optimization of the expectationmaximization algorithm (Partek Inc., St. Louis, MO, USA). The data trends and outliers were detected by Principal Component Analysis (PCA). The RNA-Seq data was normalized by using $\log _{2}$ counts per million (CPM) with an offset of 1 . Batch effect was removed between two sequencing rounds of the same biological sample. Differential analyses were performed using Partek $^{\mathrm{TM}}$ GSA with an FDR $q$-value $<.05$ and a fold change of 1.3 in aged vs. restored, 1.45 in Restored vs. Young, and 1.65 in Aged vs Young. The fold change cutoff was based on point of maximum curvature in the ranked fold changes in each comparison. The analyses resulted in 2,140 genes. The differences in gene expression were visualized by hierarchal clustering using Morpheus. Clusters were then identified by visual analysis as well as dendrogram branches. Top gene ontology (GO) terms for each cluster were found using STRING (Version 11) and the significant pathways and functions were displayed next to the hierarchal clustering [66]. Additionally, pathway and functional analyses were done by Gene Set Enrichment Analysis (GSEA). False discovery rate of $\leq 0.05$ was used as a cutoff to select significantly up or downregulated pathways. 


\section{Ingenuity pathway analysis (IPA) - hematological effects analysis}

Pathways of genes linked to hematological functions were selected using Ingenuity Pathway Analyses (IPA, QIAGEN Inc.,). We ranked the pathways by Significance score, defined as $-\log _{10} \mathrm{~B}-\mathrm{H} p$ value times activation $\mathrm{z}$-score. We retained the pathways associated with hematological functions that passed a significance score threshold of $>2$.

\section{MiR Seq}

Data analyses were performed using CLC Genomics Workbench (Qiagen) according the following data workflow: (a) Fastq files were imported into the analysis suite, (b) sequences were trimmed to remove poor quality and short reads, (c) trimmed reads were run through the Small RNA Analysis pipeline, (d) extraction and counting, (e) annotation and count merging to identify expression level of each mapped miRNA. Mapped reads from individual samples were then compared to determine fold change for each miRNA.

\section{MiRNA target prediction and network analyses}

All miRNAs exhibiting greater than 100 mappable reads were analyzed. Expression data from NGS was analyzed in silico by IPA to predict miRNA targets and downstream signaling networks. Differentially expressed exosomal and intracellular miRNA (1.4-fold cutoff) between young and aged isochronic, and aged isochronic and heterochronic samples were uploaded to the IPA suite for Core Network Analysis. Predicted networks from the Core Analyses were then simultaneously linked using Comparison Analyses to identify the MV-cell interactome during heterochronic restoration. Potential mRNA targets of candidate miRNAs were determined using the miRNA Target Filter. The source of the miRNA-mRNA relationship and the confidence of the relationship predictions were from TargetScan (http://www.targetscan.org/) and the experimentally observed relationships were from TarBase (http://diana.imis.athena-innovation.gr). mRNA target selection was based on target rank score, where the highest ranked targets were common to the most candidate miRNA (score $=6$ ) and the lowest ranked targets to the least candidate miRNA (score $=1$ ). Potential interaction with the MV - cell interactome was evaluated by creating a mock mRNA target expression profile (10-fold downregulation) to generate a Core Analysis network that could be likened using the Comparison Analysis tool. Candidates whose predicted networks converged with the interactome were selected for additional evaluation.

\section{Targets of validated miRNAs}

Analyses of 6 miRNAs for predicted targets were performed with TargetScan human database. A total of
6101 potential targets were evaluated, with a number of common targets within the group of 6 miRNA displayed within the descending concentric circles. 25 targets were identified that met the following conditions: $(1) \geq$ 4 common hits among the miRNA group, including miR-619 or miR-1303 or, (2) $\leq 3$ common hits among the group, including miR-619 and miR-1303. Predicted expression of these targets was analyzed by IPA and the resulting network predictions compared to the young exosomal and aged heterochronic intracellular miRNA interactome. Selected targets were tabulated and then pared down based on expression in relevant tissues, namely they encode verified protein and, their expression is not limited solely to neural tissue.

\section{qPCR MiRNA array analyses}

Total RNA (500 ng) was isolated from MVs using the miRCURY RNA Isolation Kit and reverse-transcribed with the miScript II RT Kit. 20 ng of cDNA was used for qPCR with the human miFinder miRNA Array, with cycling conditions of $94^{\circ} \mathrm{C}$ for $15 \mathrm{~min}, 40$ cycles at $94^{\circ} \mathrm{C}$ for 10 seconds, $55^{\circ} \mathrm{C}$ for $30 \mathrm{secs}, 70^{\circ} \mathrm{C}$ for $30 \mathrm{secs}$, followed by melt curve analysis. The data were analyzed with the online miScript miRNA PCR Array data analysis tool (SABiosciences). The miRNAs identified by microarray and NGS were validated by real time PCR with miScript primer assays using similar cycling and analysis schemes. Total RNA ( $2 \mu \mathrm{g})$ was also isolated from cells, as described above, for profiling of downstream miRNA targets by real time PCR using primers listed above and the following cycling conditions: $95^{\circ} \mathrm{C}$ for 15 mins, 40 cycles at $94^{\circ} \mathrm{C}$ for $15 \mathrm{secs}, 51^{\circ} \mathrm{C}$ for $30 \mathrm{secs}, 72^{\circ} \mathrm{C}$ for 30 secs, followed by melt curve analysis. Analyses were performed with Qiagen PCR Array Data Analysis Software, as described above.

\section{Nucleofection of miRNA mimics, miRNA inhibitors and siRNA}

Aged cells (107/sample) were nucleofected with miRNA mimics (Qiagen), miRNA inhibitors (Qiagen), negative control siRNA (Qiagen), negative control miRNA inhibitor (Qiagen) or downstream target candidate siRNAs (Origene) using the Amaxa P3 Primary Cell 4DNucleofector X Kit (Lonza) on a 4D Nucleofector device (Lonza), according to manufacturer's specific protocol. Briefly, CD34 ${ }^{+}$cells were nucleofected with $60 \mathrm{nM}$ of total miRNA mimics, miRNA inhibitors or siRNA using the "human $\mathrm{CD}_{3} 4^{+}$cell" program. Real time PCR for miRNA levels were similar $(p>0.05)$ between restored CD34+ cells and those subjected to nucleofection.

\section{Sorting of breast cancer stem cells (CSCs)}

MDA-MB-231 breast cancer cells were stably transfected with pEGFP1-Oct3/4, as previously 
described [53]. The CSCs were selected as the top 5\% cells with the highest GFP intensity $\left(\mathrm{Oct} 4{ }^{\mathrm{hi}}\right)$ and then sorted with the FACSAria II cell sorter (BD Biosciences).

\section{In vivo studies}

The use of mice was approved by Rutgers Institutional Animal Care and Use Committee (Newark Campus, $\mathrm{NJ})$. Mice were housed in an AAALAC-accredited facility.

\section{Humanization (huNSG)}

Female NSG mice (NOD.Cg-Prkdcscid Il2rgtmlWjll SzJNOD-scid IL2Rgamman ${ }^{\text {null }}$, 5 wks) were obtained from Jackson Laboratories (Bar Harbor, ME). These mice lack the major immune cells such as T-cells, B-cells, macrophages and NK cells. After 1 wk acclimatization, the NSG were humanized as described [67-69]. NSG mice were subjected to $150 \mathrm{cGy}$ whole body $\gamma$-irradiation using a Mark-I cesium irradiator unit. At $5 \mathrm{~h}$ post-irradiation, the mice were injected intravenously with $5 \times 10^{5}$ human $\mathrm{CD}^{2} 4^{+}$cells isolated from aged or young MPBs. At 9 and 13 wks posttransplantation, we assessed the mice for chimerism by flow cytometry for human CD45. Blood cells were colabeled with anti-human CD45-APC and anti-mouse CD45-FITC.

\section{In vivo restoration}

huNSG with aged CD34+ cells were transplanted by intravenous injection of $5 \times 10^{5}$ autologous aged cells from 7-day CD3-depleted isochronic (non-restored) or heterochronic (restored) cultures. Control mice were injected with sterile PBS. \% huCD45+ cells were calculated from total nucleated cells; $\%$ huCD34+ cells were calculated from total huCD45+ cells.

\section{Serial transplant}

Mice were injected with $10^{5}$ huCD34+ cells taken at the end point of the first set of transplants from the three groups.

\section{MiRNA-based in vivo restoration}

The miRNA-based studies were performed as above, except for a second injection with $60 \mathrm{nM}$ miR-619, miR-combo (miR-619, -1303, 4497) or control miR. The cells were transfected with HiPerFect reagent and then cultured for 7 days. CD3+-depleted cells were transplanted as above. At the end point of 14-15 wks post-transplant, blood, femurs and spleens were harvested for biochemical, phenotypic and functional analyses. Major organs were also harvested for histological assessment. Tissue embedding, processing and staining were performed by the Digital Imaging and Histology Core of Rutgers-New Jersey Medical School
Cancer Center (Newark, NJ). Histologic findings were confirmed on H\&E slides by a board-certified veterinary pathologist.

\section{NK function in mice with breast cancer stem cell (CSC)}

Nude female BALB/c mice (6 wks) were injected with CSCs for established dormancy in femurs as described [53]. The CSCs were isolated as outlined above. Mice with dormant cancer cells were injected with $10^{6}$ restored or unrestored aged MPBs. After one month, mice were studied for human chimerism and GFP cells were analyzed by real time PCR for GFP. Groups of 10 mice were followed for one year for survival.

The role for NK cell in targeting dormant breast cancer cells in mice was studied with NSG due to the lack of endogenous NK cells. The method followed procedure used for nude $\mathrm{BALB} / \mathrm{c}$ mice. The only modification is we performed parallel studies by depleting NK cells by phenotype. We validated NK depletion by flow cytometry and by function using cytotoxic assay.

\section{Immunohistochemistry}

Immunohistochemistry for human pan cytokeratin and Ki67 in murine femurs was performed as described [37]. Briefly antigen was retrieved from deparaffinized sections of mouse femurs by heating at $56^{\circ} \mathrm{C}$ overnight. After this the slides were dewaxed with xylene and ethanol then rehydrated, fixed and permeabilized with $0.1 \%$ Triton X. Slides were then washed $3 x$ in $1 x$ PBS and then incubated overnight at $37^{\circ} \mathrm{C}$ in a humidified chamber with primary antibodies at 1/500 final dilution for anti-cytokeratin and antiKi67. The slides were washed and then incubated ( $2 \mathrm{hrs}$ at room temp) in a humidified chamber with fluorescence-tagged secondary antibodies at 1/1000 final dilution: AlexFluor 405 for cytokeratin and rhodamine for Ki67. The slides were washed then covered with 1x PBS and then immediately analyzed on the EVOS FL Auto 2 Imaging System (ThermoFisher Scientific). Tissues from scraped femurs were placed on slides and then similarly imaged.

\section{Co-culture between natural killer (NK-/+) and CSCs}

NK cell depletion in the restored and unrestored MPBs was conducted with human CD56 microbeads from Millitenyi (Auburn, CA, USA). The method followed manufacturer's instruction. Co-cultures were performed with $10^{5}$ breast CSCs and $10^{7}$ restored MPB, with or without NK cells. After $24 \mathrm{~h}$, the number of CSCs were determined by the number 
of GFP+ breast cancer cells using fluorescence microscopy (Evos FL2 auto).

\section{NK cell assay}

\section{${ }^{51}$ Cr release}

NK cell function was determined by the $\left[{ }^{51} \mathrm{Cr}\right]$ radionuclide assay for cytotoxicity, which was performed as described previously [70]. Briefly, the K562 cell line was used as targets (T), and MPBs as effector $(\mathrm{E})$ cells. K562 cells $\left(5 \times 10^{6} / \mathrm{ml}\right)$ were labeled with $200 \mu \mathrm{Ci}$ of ${ }^{51} \mathrm{Cr}$ (PerkinElmer, Wellesley, MA). After labeling, the K562 cells were washed three times and then resuspended at $105 / \mathrm{mL}$ in RPMI $1640+10 \%$ FCS. The effector MPBs were resuspended at $10^{7} / \mathrm{mL}$ RPMI $1640+10 \%$ FCS. Equal volumes $(100 \mu \mathrm{l})$ of effector and target were added to round bottom 96-well Corning plates (Millipore Sigma) in quadruplicates at E:T ratios of 100:1, 50:1, 25:1 and 12.5:1. Spontaneous $\left[{ }^{51} \mathrm{Cr}\right]$ release was determined by incubating targets alone, and total release was determined in parallel incubations with $1 \%$ Triton X-100. After $4 \mathrm{~h}$ of incubation, cell-free supernatants were collected, and the amount of $\left[{ }^{51} \mathrm{Cr}\right]$ release was determined in a $\gamma$ counter. The percentage lysis was calculated as follows: [experimental point $(\mathrm{dpm})$ - spontaneous release $(\mathrm{dpm})] /[$ total release $(\mathrm{dpm})$ - spontaneous release $(\mathrm{dpm})] \times 100$. Values of spontaneous release were $<1 \%$ of total release. The average technical replicates were plotted on a graph of E:T vs. \% Lysis. The lytic units (LU) were determined as described (Bryant et al., 1992). One LU was assigned as the number of effector cells that lysed $20 \%$ of the target cells. Total LU is the number in $10^{7}$ effectors. Each replicate was used to calculate the total LU then plotted on the same experimental point as mean \pm SD.

\section{Carboxyfluorescein succinimidyl ester (CFSE/ 7-AAD)}

Cytotoxicity assay was performed with CFSE/7-AAD Cell Cytotoxicity kit (Cayman Chemical, Ann Arbor, MI), following manufacturer's instructions. K562 cells $\left(10^{7}\right)$ were labeled with CFSE dye for 15 mins and then washed twice. Cells were diluted to $10^{5} / \mathrm{ml}$ and incubated for $30 \mathrm{mins}$ at $37^{\circ} \mathrm{C}$. Day 7 cultures of restored or unrestored aged MPBs were used as effector cells. The effector and target cells were added into 12-well plates at the following E:T ratios: $0: 1, \quad 6.25: 1, \quad 12.5: 1$ and 25:1. The plates were incubated for $4 \mathrm{~h}$ at $37^{\circ} \mathrm{C}$. Cells were harvested and stained with 7 -AAD. Events $(50,000)$ were acquired on FACSCalibur flow cytometer. Data were analyzed using Cellquest pro software (BD Biosciences). Target cells stained only with 7-AAD were used to calculate spontaneous lysis while effector cells stained only with 7-AAD were used to detect dead effector cells. The \% lysis was calculated as [Cells positive for both CFSE and 7-AAD/Total CFSE labelled cells] $\times 100-$ spontaneous lysis.

\section{T-Cell activation assay}

T-cell activation was determined using the T-Cell Activation/Expansion Kit. Briefly, anti-biotin MACSiBead Particles were loaded with CD2, CD3, and CD28 antibodies. Cells from 7-day isochronic or heterochronic cultures, or MNCs isolated from huNSG mouse blood by Ficoll-Hypaque density gradient, were incubated with loaded anti-biotin MACSiBead Particles at a 1:2 bead to cell ratio for $72 \mathrm{~h}$ to activate T-cells. Addition of unloaded MACSiBead Particles served as negative control. After $72 \mathrm{~h}$, cells were fluorescently labeled using CD45-FITC, CD4-PE, CD25-PerCPCy5.5 and CD8-APC to determine T-cell activation status by flow cytometry.

\section{Statistical analyses}

Statistical analyses were performed with ANOVA and Tukey-Kramer multiple comparisons test. For array and NGS expression analyses, average linkage was used for clustering and Pearson correlation analysis used for distance measurement to generate heatmaps and hierarchically cluster genes. $P<0.05$ was considered significant.

\section{AUTHOR CONTRIBUTIONS}

The work was conceptualized by SJG and PR; All authors were involved in conducting the experiments; SJG submitted the original draft; ME, OAS, LSS, RJD and SA analyzed the sequencing data; All authors edited the manuscript.

\section{ACKNOWLEDGMENTS}

This work was supported by a grant from the Bosarge Family Office. Thanks to Professor Rakesh Kumar for critical input on the manuscript.

\section{CONFLICTS OF INTEREST}

The authors declare no conflicts of interest related to this study.

\section{REFERENCES}

1. Niccoli T, Partridge L. Ageing as a risk factor for disease. Curr Biol. 2012; 22:R741-52.

https://doi.org/10.1016/j.cub.2012.07.024 PMID:22975005 
2. López-Otín C, Blasco MA, Partridge L, Serrano $M$, Kroemer G. The hallmarks of aging. Cell. 2013; 153:1194-217.

https://doi.org/10.1016/i.cell.2013.05.039

PMID:23746838

3. Rando TA, Chang HY. Aging, rejuvenation, and epigenetic reprogramming: resetting the aging clock. Cell. 2012; 148:46-57.

https://doi.org/10.1016/i.cell.2012.01.003

PMID:22265401

4. Kuilman T, Michaloglou C, Mooi WJ, Peeper DS. The essence of senescence. Genes Dev. 2010; 24:2463-79. https://doi.org/10.1101/gad.1971610 PMID:21078816

5. Riera CE, Dillin A. Can aging be 'drugged'? Nat Med. 2015; 21:1400-05.

https://doi.org/10.1038/nm.4005

PMID:26646496

6. Shlush LI. Age-related clonal hematopoiesis. Blood. 2018; 131:496-504. https://doi.org/10.1182/blood-2017-07-746453 PMID:29141946

7. Kovtonyuk LV, Fritsch K, Feng X, Manz MG, Takizawa $\mathrm{H}$. Inflamm-Aging of Hematopoiesis, Hematopoietic Stem Cells, and the Bone Marrow Microenvironment. Front Immunol. 2016; 7:502.

https://doi.org/10.3389/fimmu.2016.00502 PMID:27895645

8. Pang WW, Schrier SL, Weissman IL. Age-associated changes in human hematopoietic stem cells. Semin Hematol. 2017; 54:39-42.

https://doi.org/10.1053/i.seminhematol.2016.10.004 PMID:28088986

9. Guidi N, Sacma M, Ständker L, Soller K, Marka G, Eiwen K, Weiss JM, Kirchhoff F, Weil T, Cancelas JA, Florian MC, Geiger $\mathrm{H}$. Osteopontin attenuates agingassociated phenotypes of hematopoietic stem cells. EMBO J. 2017; 36:1463.

https://doi.org/10.15252/embj.201796968

PMID:28507084

10. Franceschi $C$, Bonafè $M$, Valensin S, Olivieri F, De Luca M, Ottaviani E, De Benedictis G. Inflamm-aging. An evolutionary perspective on immunosenescence. Ann N Y Acad Sci. 2000; 908:244-54. https://doi.org/10.1111/i.1749-6632.2000.tb06651.x PMID:10911963

11. Davizon-Castillo P, McMahon B, Aguila S, Bark D, Ashworth K, Allawzi A, Campbell RA, Montenont E, Nemkov T, D'Alessandro A, Clendenen N, Shih L, Sanders NA, et al. TNF- $\alpha$-driven inflammation and mitochondrial dysfunction define the platelet hyperreactivity of aging. Blood. 2019; 134:727-40. https://doi.org/10.1182/blood.2019000200 PMID: $\underline{31311815}$

12. Ganuza M, Hall T, Finkelstein D, Wang YD, Chabot A, Kang G, Bi W, Wu G, McKinney-Freeman S. The global clonal complexity of the murine blood system declines throughout life and after serial transplantation. Blood. 2019; 133:1927-42. https://doi.org/10.1182/blood-2018-09-873059 PMID: 30782612

13. Hennrich $\mathrm{ML}$, Romanov $\mathrm{N}$, Horn $\mathrm{P}$, Jaeger $\mathrm{S}$, Eckstein V, Steeples V, Ye F, Ding X, Poisa-Beiro L, Lai MC, Lang $B$, Boultwood J, Luft T, et al. Cell-specific proteome analyses of human bone marrow reveal molecular features of age-dependent functional decline. Nat Commun. 2018; 9:4004. https://doi.org/10.1038/s41467-018-06353-4 PMID: $\underline{30275468}$

14. Kim YW, Koo BK, Jeong HW, Yoon MJ, Song R, Shin J, Jeong DC, Kim SH, Kong YY. Defective Notch activation in microenvironment leads to myeloproliferative disease. Blood. 2008; 112:4628-38. https://doi.org/10.1182/blood-2008-03-148999 PMID: 18818392

15. Song Z, Zhang J, Ju Z, Rudolph KL. Telomere dysfunctional environment induces loss of quiescence and inherent impairments of hematopoietic stem cell function. Aging Cell. 2012; 11:449-55. https://doi.org/10.1111/j.1474-9726.2012.00802.x PMID:22284665

16. Jaiswal S, Ebert BL. Clonal hematopoiesis in human aging and disease. Science. 2019; 366:eaan4673.

https://doi.org/10.1126/science.aan4673 PMID:31672865

17. Ho YH, Del Toro R, Rivera-Torres J, Rak J, Korn C, García-García A, Macías D, González-Gómez C, Del Monte A, Wittner M, Waller AK, Foster HR, LópezOtín C, et al. Remodeling of Bone Marrow Hematopoietic Stem Cell Niches Promotes Myeloid Cell Expansion during Premature or Physiological Aging. Cell Stem Cell. 2019; 25:407-18.e6. https://doi.org/10.1016/j.stem.2019.06.007 PMID:31303548

18. Lee LO, James P, Zevon ES, Kim ES, Trudel-Fitzgerald C, Spiro A 3rd, Grodstein F, Kubzansky LD. Optimism is associated with exceptional longevity in 2 epidemiologic cohorts of men and women. Proc Natl Acad Sci U S A. 2019; 116:18357-62. https://doi.org/10.1073/pnas.1900712116 PMID:31451635

19. Mora F, Segovia G, Del Arco A, de Blas M, Garrido P. Stress, neurotransmitters, corticosterone and bodybrain integration. Brain Res. 2012; 1476:71-85. 
https://doi.org/10.1016/i.brainres.2011.12.049 PMID:22285436

20. de Haan G, Lazare SS. Aging of hematopoietic stem cells. Blood. 2018; 131:479-87.

https://doi.org/10.1182/blood-2017-06-746412 PMID:29141947

21. Hazeldine J, Lord JM. Innate immunesenescence: underlying mechanisms and clinical relevance. Biogerontology. 2015; 16:187-201. https://doi.org/10.1007/s10522-014-9514-3 PMID:25009085

22. Kyoizumi S, Kubo Y, Kajimura J, Yoshida K, Imai K, Hayashi T, Nakachi K, Young LF, Moore MA, van den Brink MR, Kusunoki Y. Age-associated changes in the differentiation potentials of human circulating hematopoietic progenitors to T- or NK-lineage cells. J Immunol. 2013; 190:6164-72.

https://doi.org/10.4049/jimmunol.1203189 PMID:23670190

23. Mccay CM, Pope F, Lunsford W, Sperling G, Sambhavaphol P. Parabiosis between old and young rats. Gerontologia. 1957; 1:7-17.

https://doi.org/10.1159/000210677 PMID:13405201

24. Conboy IM, Conboy MJ, Wagers AJ, Girma ER, Weissman IL, Rando TA. Rejuvenation of aged progenitor cells by exposure to a young systemic environment. Nature. 2005; 433:760-64.

https://doi.org/10.1038/nature03260

PMID:15716955

25. Katsimpardi L, Litterman NK, Schein PA, Miller CM, Loffredo FS, Wojtkiewicz GR, Chen JW, Lee RT, Wagers AJ, Rubin LL. Vascular and neurogenic rejuvenation of the aging mouse brain by young systemic factors. Science. 2014; 344:630-34.

https://doi.org/10.1126/science.1251141

PMID:24797482

26. Shytikov D, Balva O, Debonneuil E, Glukhovskiy P, Pishel I. Aged mice repeatedly injected with plasma from young mice: a survival study. Biores Open Access. 2014; 3:226-32.

https://doi.org/10.1089/biores.2014.0043

PMID:25371859

27. Sinha $M$, Jang $Y C$, Oh J, Khong D, Wu EY, Manohar R, Miller C, Regalado SG, Loffredo FS, Pancoast JR, Hirshman MF, Lebowitz J, Shadrach JL, et al. Restoring systemic GDF11 levels reverses age-related dysfunction in mouse skeletal muscle. Science. 2014; 344:649-52.

https://doi.org/10.1126/science.1251152

PMID:24797481

28. Villeda SA, Plambeck KE, Middeldorp J, Castellano JM, Mosher KI, Luo J, Smith LK, Bieri G, Lin K, Berdnik D,
Wabl R, Udeochu J, Wheatley EG, et al. Young blood reverses age-related impairments in cognitive function and synaptic plasticity in mice. Nat Med. 2014; 20:659-63.

https://doi.org/10.1038/nm.3569

PMID:24793238

29. Ocampo A, Reddy P, Martinez-Redondo P, PlateroLuengo A, Hatanaka F, Hishida T, Li M, Lam D, Kurita M, Beyret E, Araoka T, Vazquez-Ferrer E, Donoso D, et al. In Vivo Amelioration of Age-Associated Hallmarks by Partial Reprogramming. Cell. 2016; 167:1719-33.e12.

https://doi.org/10.1016/j.cell.2016.11.052

PMID:27984723

30. Poulos MG, Ramalingam P, Gutkin MC, Llanos $P$, Gilleran K, Rabbany SY, Butler JM. Endothelial transplantation rejuvenates aged hematopoietic stem cell function. J Clin Invest. 2017; 127:4163-78.

https://doi.org/10.1172/JCI93940

PMID:29035282

31. Wahlestedt $M$, Erlandsson $E$, Kristiansen $T$, Lu R, Brakebusch C, Weissman IL, Yuan J, Martin-Gonzalez J, Bryder D. Clonal reversal of ageing-associated stem cell lineage bias via a pluripotent intermediate. Nat Commun. 2017; 8:14533.

https://doi.org/10.1038/ncomms14533

PMID:28224997

32. Kyoizumi S, Kubo Y, Misumi M, Kajimura J, Yoshida K, Hayashi T, Imai K, Ohishi W, Nakachi K, Young LF, Shieh JH, Moore MA, van den Brink MR, Kusunoki Y. Circulating Hematopoietic Stem and Progenitor Cells in Aging Atomic Bomb Survivors. Radiat Res. 2016; 185:69-76.

https://doi.org/10.1667/RR14209.1

PMID:26720799

33. Leins $H$, Mulaw $M$, Eiwen $K$, Sakk V, Liang $Y$, Denkinger M, Geiger $H$, Schirmbeck R. Aged murine hematopoietic stem cells drive aging-associated immune remodeling. Blood. 2018; 132:565-76. https://doi.org/10.1182/blood-2018-02-831065 PMID:29891535

34. Auer F, Ingenhag D, Bhatia S, Enczmann J, Cobaleda C, Sanchez-Garcia I, Borkhardt A, Hauer J. GEMMs addressing Pax5 loss-of-function in childhood pB-ALL. Eur J Med Genet. 2016; 59:166-72.

https://doi.org/10.1016/j.ejmg.2015.11.009 PMID:26626503

35. Grimm TM, Dierdorf NI, Betz K, Paone C, Hauck CR. PPM1F controls integrin activity via a conserved phospho-switch. J Cell Biol. 2020; 219:e202001057. https://doi.org/10.1083/jcb.202001057 PMID:33119040 
36. Hazeldine J, Lord JM. The impact of ageing on natural killer cell function and potential consequences for health in older adults. Ageing Res Rev. 2013; 12:1069-78.

https://doi.org/10.1016/j.arr.2013.04.003

PMID:23660515

37. Bliss SA, Sinha G, Sandiford OA, Williams LM, Engelberth DJ, Guiro K, Isenalumhe LL, Greco SJ, Ayer S, Bryan M, Kumar R, Ponzio NM, Rameshwar P. Mesenchymal Stem Cell-Derived Exosomes Stimulate Cycling Quiescence and Early Breast Cancer Dormancy in Bone Marrow. Cancer Res. 2016; 76:5832-44.

https://doi.org/10.1158/0008-5472.CAN-16-1092 PMID:27569215

38. Hao QL, Thiemann FT, Petersen D, Smogorzewska EM, Crooks GM. Extended long-term culture reveals a highly quiescent and primitive human hematopoietic progenitor population. Blood. 1996; 88:3306-13.

https://doi.org/10.1182/blood.V88.9.3306.bloodjour nal8893306

PMID:8896394

39. Fitchen JH, Le Fèvre $C$, Ferrone $S$, Cline MJ. Expression of la-like and HLA-A,B antigens on human multipotential hematopoietic progenitor cells. Blood. 1982; 59:188-90. https://doi.org/10.1182/blood.V59.1.188.188 PMID: 6947831

40. Greaves M, Robinson J, Delia D, Sutherland R, Newman R, Sieff C. Mapping cell surface antigen expression of haemopoietic progenitor cells using monoclonal antibodies. Ciba Found Symp. 1981; 84:109-29.

https://doi.org/10.1002/9780470720660.ch7 PMID: 6168448

41. Caux C, Favre C, Saeland S, Duvert V, Mannoni P, Durand I, Aubry JP, de Vries JE. Sequential loss of CD34 and class II MHC antigens on purified cord blood hematopoietic progenitors cultured with IL-3: characterization of CD34, HLA-DR+ cells. Blood. 1989; 74:1287-94. https://doi.org/10.1182/blood.V74.4.1287.1287 PMID:2475184

42. Buschow SI, van Balkom BW, Aalberts $M$, Heck AJ, Wauben M, Stoorvogel W. MHC class II-associated proteins in B-cell exosomes and potential functional implications for exosome biogenesis. Immunol Cell Biol. 2010; 88:851-56.

https://doi.org/10.1038/icb.2010.64

PMID:20458337

43. Gruver AL, Hudson LL, Sempowski GD. Immunosenescence of ageing. J Pathol. 2007; 211:144-56.

https://doi.org/10.1002/path.2104

PMID: $\underline{17200946}$
44. Ovadya Y, Krizhanovsky V. Senescent cells: SASPected drivers of age-related pathologies. Biogerontology. 2014; 15:627-42. https://doi.org/10.1007/s10522-014-9529-9 PMID:25217383

45. Bartek J, Falck J, Lukas J. CHK2 kinase--a busy messenger. Nat Rev Mol Cell Biol. 2001; 2:877-86. https://doi.org/10.1038/35103059 PMID: 11733767

46. Junnila RK, List EO, Berryman DE, Murrey JW, Kopchick JJ. The GH/IGF-1 axis in ageing and longevity. Nat Rev Endocrinol. 2013; 9:366-76. https://doi.org/10.1038/nrendo.2013.67 PMID:23591370

47. Abbonante V, Gruppi C, Catarsi P, Avanzini MA, Tira ME, Barosi G, Rosti V, Balduini A. Altered fibronectin expression and deposition by myeloproliferative neoplasm-derived mesenchymal stromal cells. $\mathrm{Br} \mathrm{J}$ Haematol. 2016; 172:140-44.

https://doi.org/10.1111/bjh.13471 PMID:25940987

48. Lehmann M, Canatelli-Mallat $M$, Chiavellini P, Cónsole GM, Gallardo MD, Goya RG. Partial Reprogramming As An Emerging Strategy for Safe Induced Cell Generation and Rejuvenation. Curr Gene Ther. 2019; 19:248-54.

https://doi.org/10.2174/1566523219666190902154511 PMID:31475896

49. Mulcahy LA, Pink RC, Carter DR. Routes and mechanisms of extracellular vesicle uptake. J Extracell Vesicles. 2014; 3.

https://doi.org/10.3402/jev.v3.24641

PMID:25143819

50. Ratajczak MZ, Ratajczak J. Extracellular microvesicles/exosomes: discovery, disbelief, acceptance, and the future? Leukemia. 2020; 34:3126-35.

https://doi.org/10.1038/s41375-020-01041-z PMID: $\underline{32929129}$

51. Quesenberry P, Goldberg LR. A New Stem Cell Biology: Transplantation and Baseline, Cell Cycle and Exosomes. Adv Exp Med Biol. 2018; 1056:3-9.

https://doi.org/10.1007/978-3-319-74470-4 1 PMID:29754171

52. Naumova E, Pawelec G, Mihaylova A. Natural killer cells, ageing and cancer. Cancer Immunol Immunother. 2016; 65:367-70.

https://doi.org/10.1007/s00262-016-1817-6

PMID:26969613

53. Patel SA, Ramkissoon SH, Bryan M, Pliner LF, Dontu G, Patel PS, Amiri S, Pine SR, Rameshwar P. Delineation of breast cancer cell hierarchy identifies 
the subset responsible for dormancy. Sci Rep. 2012; 2:906.

https://doi.org/10.1038/srep00906

PMID:23205268

54. Montecino-Rodriguez E, Kong Y, Casero D, Rouault A, Dorshkind K, Pioli PD. Lymphoid-Biased Hematopoietic Stem Cells Are Maintained with Age and Efficiently Generate Lymphoid Progeny. Stem Cell Reports. 2019; 12:584-96.

https://doi.org/10.1016/i.stemcr.2019.01.016 PMID: $\underline{30799276}$

55. Pietras EM. Inflammation: a key regulator of hematopoietic stem cell fate in health and disease. Blood. 2017; 130:1693-98.

https://doi.org/10.1182/blood-2017-06-780882 PMID:28874349

56. Swindell WR, Johnston A, Xing $X$, Little A, Robichaud P, Voorhees JJ, Fisher G, Gudjonsson JE. Robust shifts in S100a9 expression with aging: a novel mechanism for chronic inflammation. Sci Rep. 2013; 3:1215. https://doi.org/10.1038/srep01215 PMID:23386971

57. Kwon JS, Everetts NJ, Wang X, Wang W, Della Croce K, Xing J, Yao G. Controlling Depth of Cellular Quiescence by an Rb-E2F Network Switch. Cell Rep. 2017; 20:3223-35. https://doi.org/10.1016/i.celrep.2017.09.007 PMID:28954237

58. Pearce DJ, Anjos-Afonso F, Ridler CM, Eddaoudi A, Bonnet D. Age-dependent increase in side population distribution within hematopoiesis: implications for our understanding of the mechanism of aging. Stem Cells. 2007; 25:828-35. https://doi.org/10.1634/stemcells.2006-0405 PMID:17158238

59. Helbling PM, Piñeiro-Yáñez E, Gerosa R, Boettcher $S$, Al-Shahrour F, Manz MG, Nombela-Arrieta C. Global Transcriptomic Profiling of the Bone Marrow Stromal Microenvironment during Postnatal Development, Aging, and Inflammation. Cell Rep. 2019; 29:331330.e4.

https://doi.org/10.1016/j.celrep.2019.11.004 PMID:31801092

60. Pentinmikko N, Iqbal S, Mana $M$, Andersson $S$, Cognetta $A B$ 3rd, Suciu RM, Roper J, Luopajärvi K, Markelin E, Gopalakrishnan S, Smolander OP, Naranjo $\mathrm{S}$, Saarinen $\mathrm{T}$, et al. Notum produced by Paneth cells attenuates regeneration of aged intestinal epithelium. Nature. 2019; 571:398-402. https://doi.org/10.1038/s41586-019-1383-0 PMID: $\underline{31292548}$
61. Joshi DD, Dang A, Yadav P, Qian J, Bandari PS, Chen K, Donnelly R, Castro T, Gascon P, Haider A, Rameshwar $P$. Negative feedback on the effects of stem cell factor on hematopoiesis is partly mediated through neutral endopeptidase activity on substance P: a combined functional and proteomic study. Blood. 2001; 98:2697-706.

https://doi.org/10.1182/blood.v98.9.2697 PMID: 11675340

62. Potian JA, Aviv H, Ponzio NM, Harrison JS, Rameshwar P. Veto-like activity of mesenchymal stem cells: functional discrimination between cellular responses to alloantigens and recall antigens. J Immunol. 2003; 171:3426-34.

https://doi.org/10.4049/jimmunol.171.7.3426 PMID: 14500637

63. Greco SJ, Patel SA, Bryan M, Pliner LF, Banerjee D, Rameshwar P. AMD3100-mediated production of interleukin-1 from mesenchymal stem cells is key to chemosensitivity of breast cancer cells. Am J Cancer Res. 2011; 1:701-15. PMID:22016821

64. Babicki S, Arndt D, Marcu A, Liang Y, Grant JR, Maciejewski A, Wishart DS. Heatmapper: webenabled heat mapping for all. Nucleic Acids Res. 2016; 44:W147-53.

https://doi.org/10.1093/nar/gkw419 PMID:27190236

65. Junge A, Refsgaard JC, Garde C, Pan X, Santos A, Alkan $F$, Anthon C, von Mering C, Workman CT, Jensen $L$, Gorodkin J. RAIN: RNA-protein Association and Interaction Networks. Database (Oxford). 2017; 2017:baw167.

https://doi.org/10.1093/database/baw167 PMID:28077569

66. Szklarczyk D, Gable AL, Lyon D, Junge A, Wyder S, Huerta-Cepas J, Simonovic M, Doncheva NT, Morris JH, Bork P, Jensen L, Mering CV. STRING v11: proteinprotein association networks with increased coverage, supporting functional discovery in genome-wide experimental datasets. Nucleic Acids Res. 2019; 47:D607-13.

https://doi.org/10.1093/nar/gky1131

PMID:30476243

67. Shultz LD, Lyons BL, Burzenski LM, Gott B, Chen X, Chaleff $S$, Kotb $M$, Gillies SD, King $M$, Mangada J, Greiner DL, Handgretinger R. Human lymphoid and myeloid cell development in NOD/LtSz-scid IL2R gamma null mice engrafted with mobilized human hemopoietic stem cells. J Immunol. 2005; 174:6477-89. https://doi.org/10.4049/iimmunol.174.10.6477 PMID:15879151 
68. Ishikawa F, Yasukawa $M$, Lyons B, Yoshida S, Miyamoto T, Yoshimoto G, Watanabe T, Akashi K, Shultz LD, Harada M. Development of functional human blood and immune systems in NOD/SCID/IL2 receptor \{gamma\} chain(null) mice. Blood. 2005; 106:1565-73.

https://doi.org/10.1182/blood-2005-02-0516

PMID:15920010

69. Gergues M, Nagula V, Bliss SA, Eljarrah A, Ayer S, Gnanavel N, Sinha G, Wu Q, Yehia G, Greco SJ, Qian J, Rameshwar P. Neuroimmune/Hematopoietic Axis with Distinct Regulation by the High-Mobility Group Box 1 in Association with Tachykinin Peptides. J Immunol. 2020; 204:879-91. https://doi.org/10.4049/jimmunol.1900582

PMID:31924647

70. Patel SA, Meyer JR, Greco SJ, Corcoran KE, Bryan M, Rameshwar P. Mesenchymal stem cells protect breast cancer cells through regulatory $T$ cells: role of mesenchymal stem cell-derived TGF-beta. J Immunol. 2010; 184:5885-94.

https://doi.org/10.4049/jimmunol.0903143

PMID:20382885 


\section{SUPPLEMENTARY MATERIALS}

\section{Supplementary Figures}
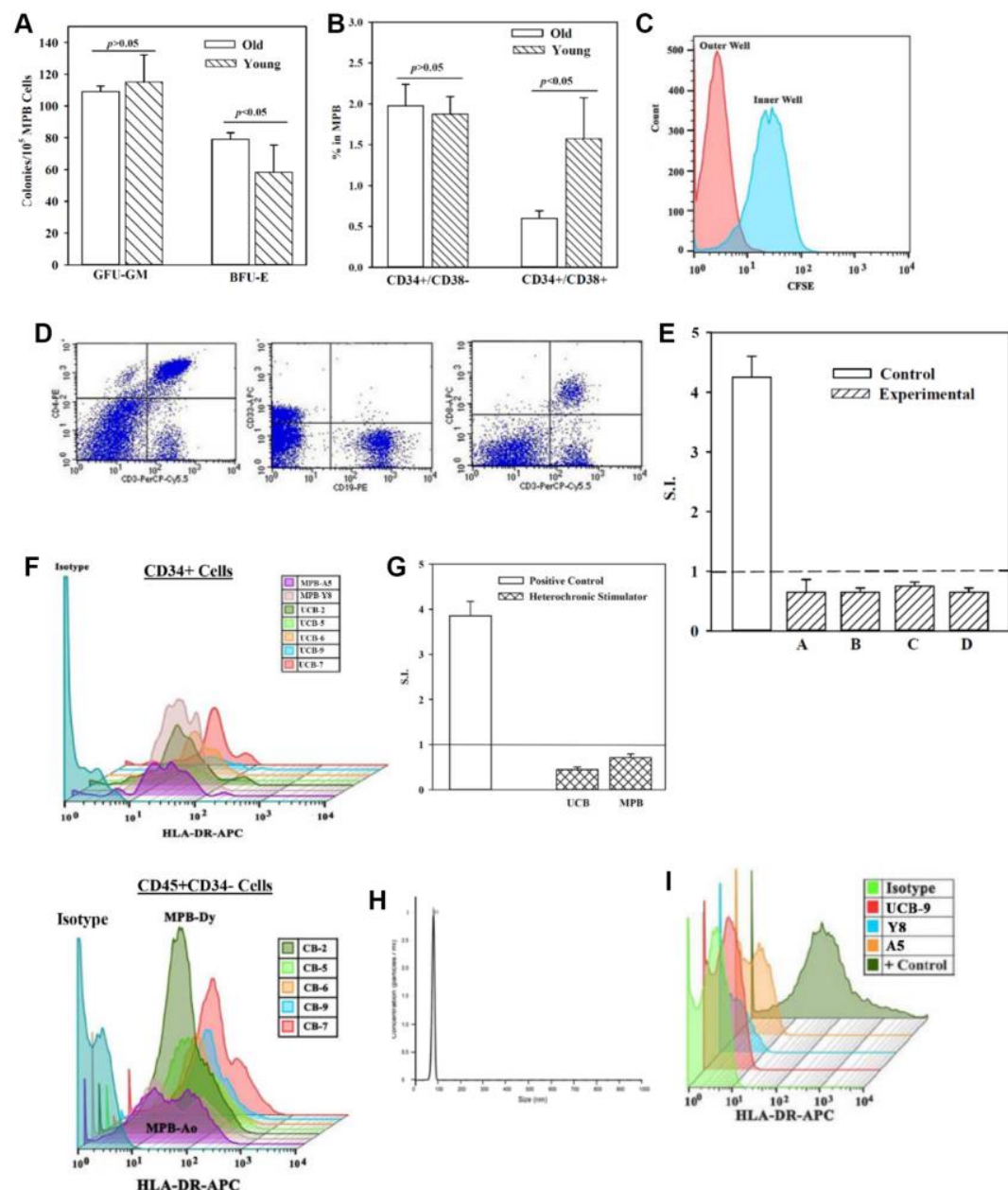

Supplementary Figure 1. (A) Clonogenic assay for CFU-GM and BFU-E with MPB cells from young and aged donors ( $n=8$ for each group, each tested in triplicate). The number of CFU-GM $/ 10^{5}$ cells are presented as the mean \pm SD. (B) Flow cytometry with cells from young and aged donors. CD45+ cells were gated for CD34 and then divided based on CD38. The results are presented as the mean MFI \pm SD for four aged and four young MPBs. (C) Heterochronic transwell cultures contained CFSE-labeled young MPBs in the inner wells and unlabeled aged MPBs in the outer wells. At weekly intervals up to week 4, the inner wells were examined for CFSE. The histogram represents the result at the 4-wk time point. (D) Representative images of flow cytometry for T- (CD3 and CD4), B- (CD19) and myeloid (CD33) cells in the aged MPBs. (E) One-way MLR with restore aged MPB as stimulator and naïve autologous aged MPB as responder. The stimulator cells were derived from heterochronic cultures with aged MPBs (arbitrarily labeled A-D), each tested with two different young MPBs in the inner wells. After 4 wks, the restored aged MPBs were $\gamma$-irradiated for testing with in the one-way MLR as stimulator cells. The responder cells were viable freshly thawed autologous MPBs. Positive control used unrestored allogeneic MPBs from young or aged donors. The results are presented as mean stimulation indices (S.I.) \pm SD for each donor, each tested with two young MPBs in duplicate. The positive controls, which represented 4 experimental points, two with allogeneic aged MPBs and 2 with allogeneic young MPBs showed similar responses and therefore plotted on the same bar. Each MLR test was performed in quadruplicate. (F) Flow cytometry for MHC-II using CD45+/CD34+ cells (top panel) and CD34-/CD45+ (bottom panel) from 5 randomly selected UCB and MPBs from a young and an aged donor. The cells were labeled with anti-HLA-DR-APC or isotype. Shown is representative of a young and an aged MPB donor. The results indicated higher density of MHC-II on CD34+ and CD34- UCB as compared to MPB from the aged young donors. (G) MLR reactions were repeated for 'E' except that UCB replaced young MPBs in the inner wells. The results are shown as the mean S.I. \pm SD from five heterochronic cultures in which four aged MPBs were restored with five different UCB. Each heterochronic culture was done in duplicate and the MLR reactions, in quadruplicates. (H) Representative histogram of MVs, isolated from the media of heterochronic cultures, by nanotracker (Nanosight, Malvern, Westborough, MA). (I) MVs were captured onto CD63-coupled beads followed by labeling with anti-HLA-DR-APC. The labeled beads were subjected to flow cytometric analyses. Representative results show the results of MVs from heterochronic cultures with UCB in the inner wells. Parallel analyses were performed with media from isochronic cultures containing young and aged MPBs. Positive control (+ control) for the flow cytometric technique used anti-CD3 activated mononuclear cells. 


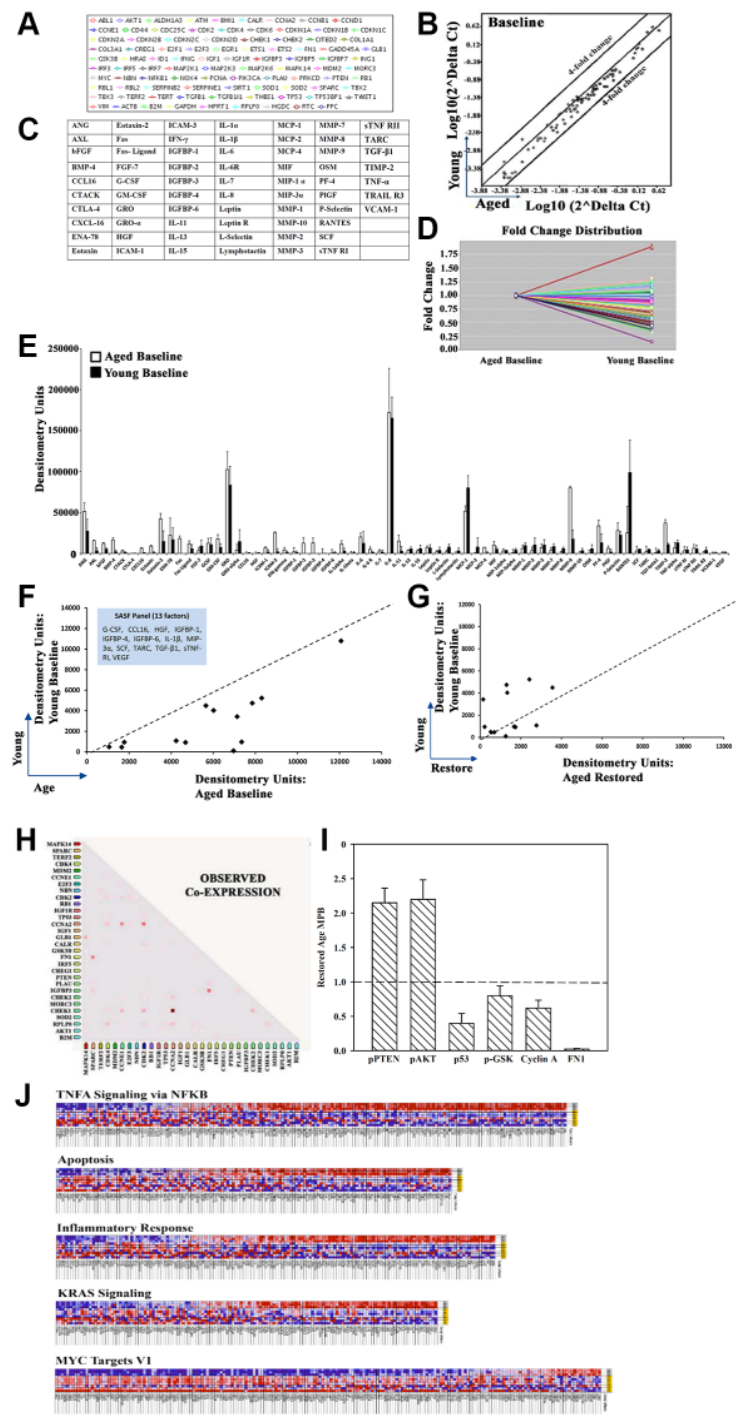

Supplementary Figure 2. (A) The 84 age/senescence-related genes in the PCR arrays. (B) The results of the analyses in ' $A$ ' were calculated as follows: $\Delta C_{t}$ between gene-of-interest and housekeeping genes and the values used to calculate fold change. Shown are the boundaries with 4-fold changes in gene expression. (C) Custom senescence-associated secretome (SASP) of 64 factors tested for released factors in aged and young bases line as well as restored samples. (D) Line plots of 4 biological replicates illustrate the fold change of proteins between aged and young baseline MPB. (E) The densitometric results of SASP analyses with media from day 1 heterochronic cultures. Densitometric units were calculated and plotted as a bar graph comparing expression of individual factors among aged and young. Results are presented as the mean \pm SD, $n=4$. (F) The dot plot shows 13 differentially expressed proteins between young and old MPB. The dotted line $y=x$ indicates no change between groups. (G) Plots similar to ' $F$ ' were made to determine similarities between young and restored aged MPBs. (H) The plots shows co-expression of genes in the 30 genes in the boxed region of Figure $1 \mathrm{H}$. The dots represent the association between genes. (I) Normalized band densities for Western blots in Figure $1 \mathrm{~J}(n=3, \pm \mathrm{SD})$. (J) The full heat maps of Figure 2D. 


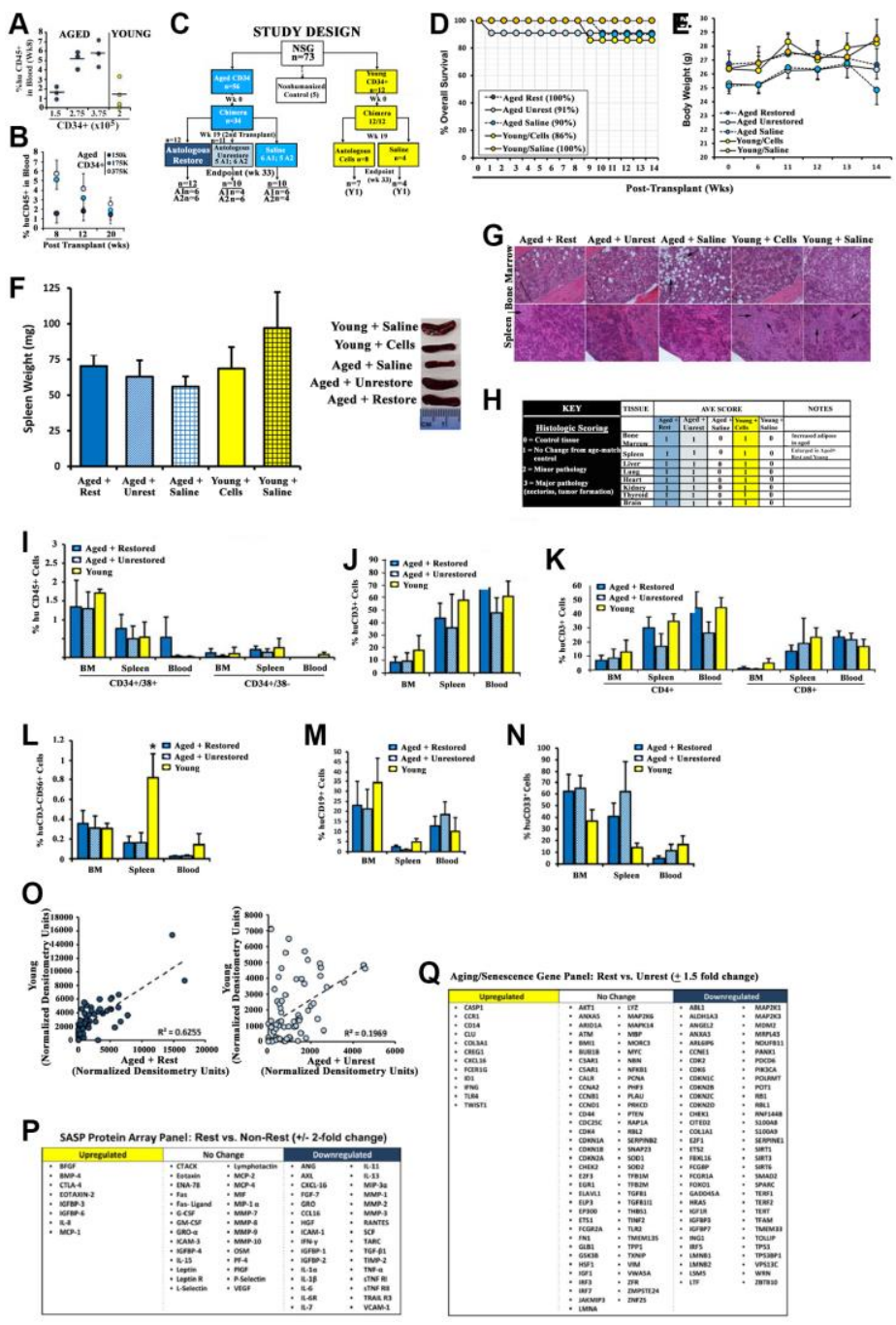

Supplementary Figure 3. Procedural and safety monitoring of huNSG mice. (A) Optimize the number of aged CD34+ cells in NSG mice to achieve chimeras. Shown is the engraftment (human chimerism) at wk 8, based on human CD45+ cells in peripheral blood. (B) The transplant in ' $A$ ' was repeated and chimera assessed up to 20 wks as for ' $A$ '. (C) Study design using huNSG to study in vivo restoration. A total of 68 irradiated mice were transplanted with aged $(n=56)$ or young $(n=12) \operatorname{CD} 34^{+}$cells. 34/56 mice transplanted with aged CD34+ cells successfully achieved chimera, based on the criteria in ' $A$ ' and ' $B$ '. $12 / 12$ mice successfully engrafted with young CD $34^{+}$cells. Cutoff for enrolling mice in the second transplant with cells from heterochronic or isochronic cultures was set at $\geq 1 \%$ huCD $45^{+}$cells in blood. Mice displaying $0.5-1 \%$ chimera were enrolled in the saline treatment arms, and mice displaying $<0.5 \%$ chimerism were not enrolled in the study. The injected cells were from two different aged donors (A1 and A2), restored/heterochronic or unrestored/isochronic (D) KaplanMeier plot for huNSG survival. (E) Body weight at wk 14 following the $2^{\text {nd }}$ transplant with restored MPB (heterochronic cultures) or from isochronic cultures with aged cells. (F) Endpoint spleen weights with representative images of the spleen at right. Results are presented as the mean \pm SEM. ${ }^{*} p \leq 0.05$ vs. control. Histologic evaluation of tissues from huNSG treatment groups at the study end-points: (G) Major organs and immune tissues were harvested and then stained by H\&E. Shown are representative sections of femurs (top panels) and spleens (bottom panels) at 10X magnification. (H) All harvested tissues were examined for tissue necrosis and tumorigenesis with the treatment groups being compared with age-matched control tissue. The black arrows at the top panel show increased adipocytes in mice femurs given only aged cells whereas similar area of adipocytes was not identified in mice with a second transplant of restored cells. The arrows on the lower panels showed increased hematopoietic activity in the spleen of mice given restored or young cells. Phenotypic analyses for human hematopoietic and immune cells in huNSG mice: Nucleated cells from blood, bone marrow (BM) and spleen were gated for huCD45 $5^{+}$. After this, the gated population was analyzed for (I) hematopoietic stem (CD34+38-) and progenitor $\left(\mathrm{CD}^{+} 4^{+} 38^{+}\right)$cells; (J) T-cells $\left(\mathrm{CD}^{+}\right)$; (K) T-helper (CD4+) and cytotoxic (CD8+) cells; (L) natural killer cells (CD3-56+); (M) B-cells (CD19+); and (N) myeloid cells (CD33+). The results are presented as the mean \pm SEM. Senescence and age-related gene and protein expression in huNSG treatment groups: (0) Scatterplots comparing senescence-associated secretory factor (SASF) expression in plasma of mice transplanted with either aged restored (left plot) or non-restored (right plot) cells compared to young. Values are normalized by background subtraction of SASF levels in nonhumanized control NSG mice. Results are presented as mean densitometry units, with description of upregulated, downregulated and no change in expression SASFs listed in (P). (Q) List of aging- and senescence-related genes whose expression is upregulated, downregulated or no change in human cells isolated from huNSG BM. Classifications in P and $\mathrm{Q}$ are based on a 1.5-fold change cutoff. 

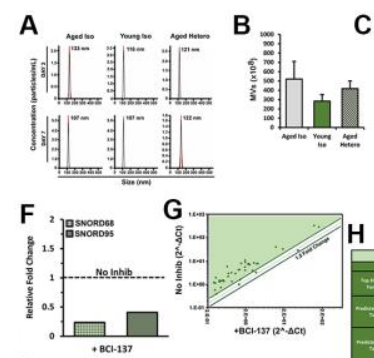

$\mathrm{H}$

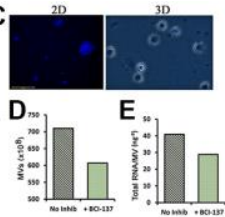

I
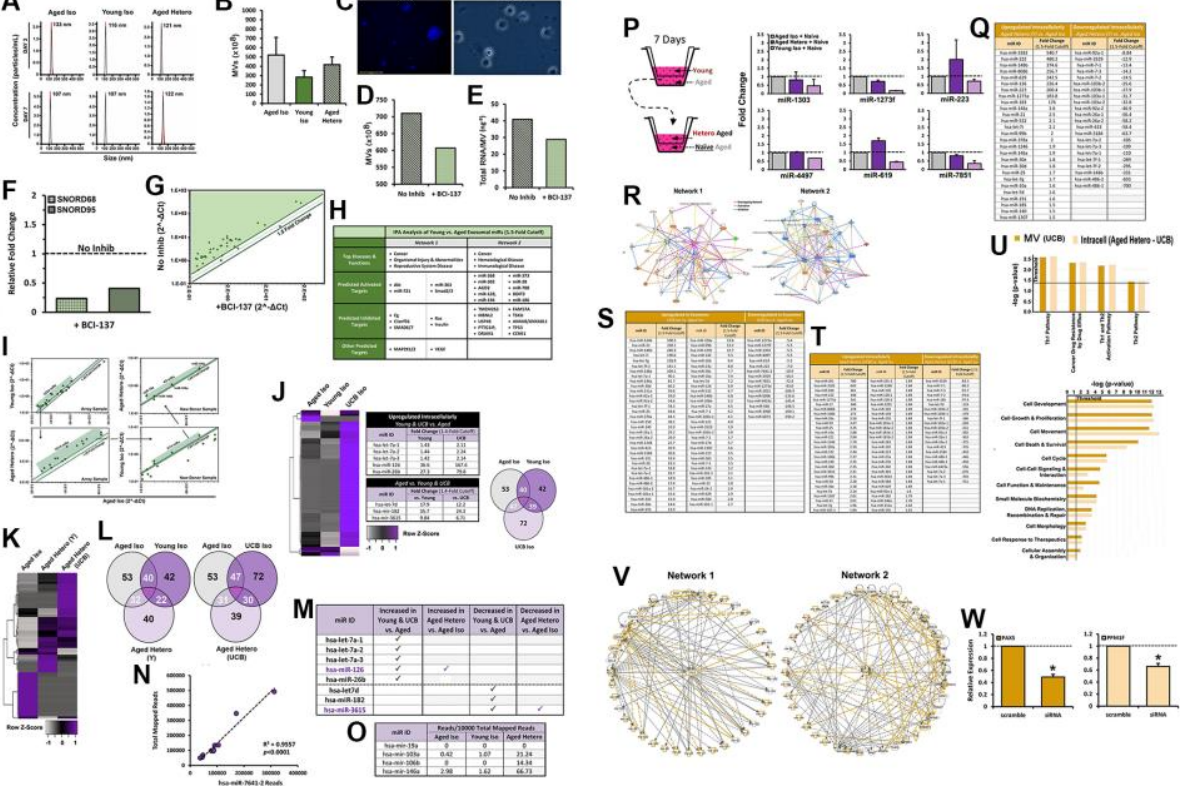

Supplementary Figure 4. MVs and their miRNAs in heterochronic (restored) and isochronic (unrestored) cultures (A-H). (A) Nanoparticle tracking analyses (NTA) of MVs from day 3 and 7 heterochronic cultures. (B) MVs in heterochronic or isochronic control cultures were isolated on days 4 and 7, and then pooled. The total number of particles were quantified by NTA, mean \pm SD, $n=4$. (C) CMAC-labeled MVs from 3-day heterochronic cultures were added to naïve aged MPBs. Shown are 2D and 3D images of MVs entering the cells (blue), imaged by EVOS fl and confocal microscopy, respectively. (D) Effect of AGO2 inhibitor (BCl-137) on MV release. MVs were collected at days 4 and 7 from the media of heterochronic cultures, which were established in the presence of $\mathrm{BCl}-137$ or vehicle (no Inhibitor). The particles were pooled for quantitation by NTA. The values are presented as the mean \pm SD, $n=4$. (E and F) MVs from 'D' were quantitated for total RNA (E) or small RNA (F). (G) MVs from ' $C$ ' were analyzed with miRNA arrays. The results are shown for enrichment of exosomal miRNAs in cultures without inhibitor vs. vehicle in a scatterplot, based on 1.5-fold cutoff. (H) Shown are the output of Ingenuity Pathway Analysis (IPA) using commonly expressed miRNAs with differential expression using 1.5-fold cutoff. The data ' $F$ ' and the analyses compared young vs. aged isochronic cultures. (I) Validation of miFinder QPCR array by individual qPCR experiments in array (left panels) and fresh donor samples (right panels). Gating scheme depicts miRNAs that are upregulated in young isochronic and heterochronic vs. aged isochronic cultures. Results are depicted by scatterplot with 1.25-fold and 1.05-fold cutoffs in array and fresh donor samples, respectively. Array and individual qPCR studies were normalized to RNU6, SNORD68 and SNORD95 and presented as fold change, with a value of 1 representing control. Characterizing the young intracellular miRNAs and ascribing a role for miRNAs in the mechanism of restoration (J-P). (J) Small RNA was purified from aged, young and UCB isochronic cultures for whole miRNA sequencing. All miRNAs exhibiting greater than 100 mappable reads were further analyzed. Differential RNA expression is denoted by heatmap, with miRNA exhibiting greater than 1.4-fold difference among aged vs. UCB and young samples. Outer area of the Venn diagrams depicts total number of intracellular miRNAs with greater than 100 mappable reads in age-matched isochronic samples. Overlapping areas represent common miRNA among samples. (K, L) Studies, similar to ' $I$ ', compared the miRNAs obtained from sequencing of aged isochronic and heterochronic (young-aged, UCB-aged) samples. (M) MiR showing differential expression in ' $J$ ' were compared to miR showing increased or decreased expression in heterochronic (aged-young) vs. aged isochronic cultures in ' $K$ ' and ' $L$ '. The results are tabulated to illustrate candidate miRNAs whose expression patterns are coincident with aged cell restoration. (N) Scatterplot depicting linear correlation between exosomal miR-7641-2 expression and total mappable reads, $n=10$. (0) Expression of early exosomal candidate miRNAs from miFinder array studies in sequencing dataset. Results are shown for isochronic and heterochronic cultures as average reads per 10000 total mapped reads. (P) To evaluate whether candidate MV miRNAs can be propagated after aged cell restoration, aged and young cells from 7-day isochronic cultures or aged cells from heterochronic culture were harvested at day 7 and transferred to fresh transwell cultures with naïve aged cells for an additional 7 days. On the $3^{\text {rd }}$ (day 10$)$ and $7^{\text {th }}$ (day 14) day of the propagation culture, MVs were isolated and probed for candidate miRNA expression by qPCR. Results were normalized to miR-7641-2 expression and presented as fold change, with a value of 1 representing control (gray bars). Results are presented as the mean \pm SEM, $n=3$, unless otherwise noted. ${ }^{*} p \leq 0.05$ vs. control. Identification of potential young MV miRNA targets in aged cells ( $Q-\mathbf{W}$ ). (Q) Up- and downregulated intracellular miRNAs comparing aged heterochronic (aged-young) vs. isochronic cultures with a 1.5-fold cutoff, and their (R) predicted activation/inhibition networks after IPA. Up- and downregulated (S) MV miRNAs comparing UCB vs. aged isochronic and (T) intracellular miRNAs comparing aged heterochronic (aged-UCB) vs. isochronic cultures with a 1.5-fold cutoff. (U) Illustration of the top cellular functions (left graph) and canonical pathways (right graph) predicted by (V) these networks are shown. (W) Validation of siRNA knockdown of target candidates in cells from aged donors. Results were normalized to $\beta$-Actin expression and presented as fold change, with a value of 1 representing control (scrambled siRNA). Results are presented as the mean $\pm \mathrm{SEM}, n=3$, unless otherwise noted. ${ }^{*} p \leq 0.05$ vs. control. 

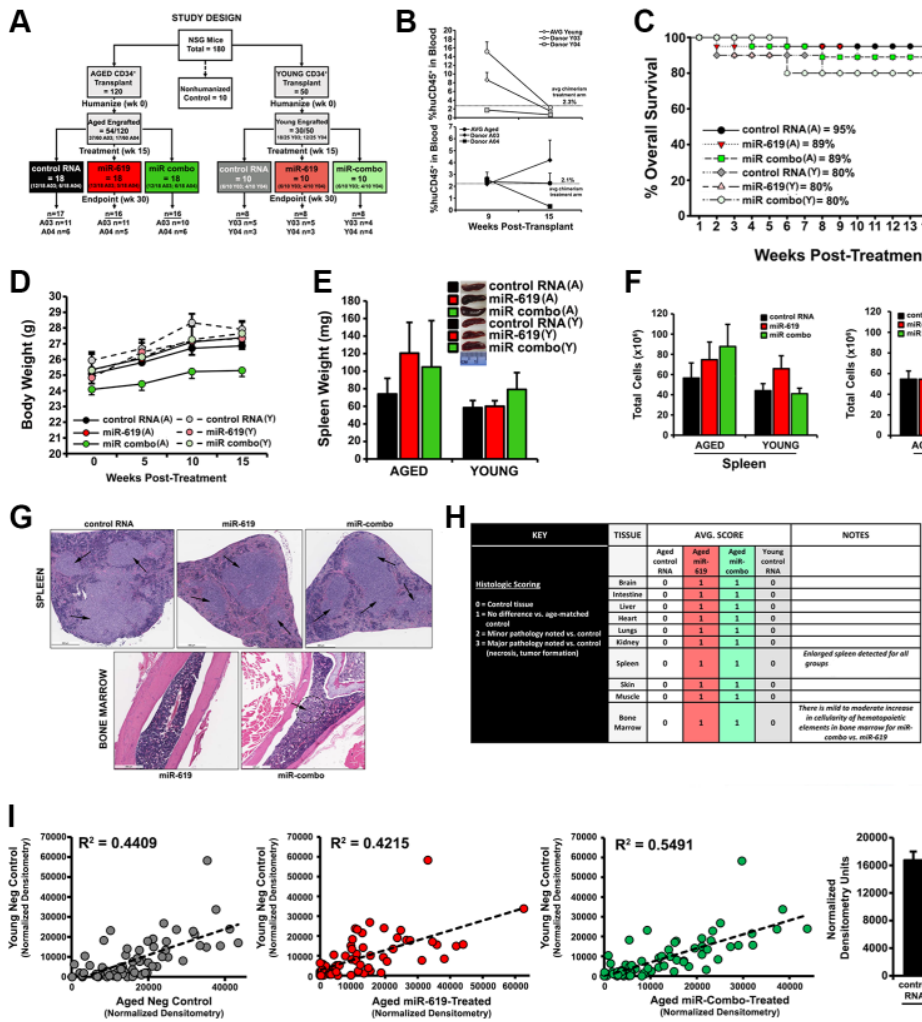

I
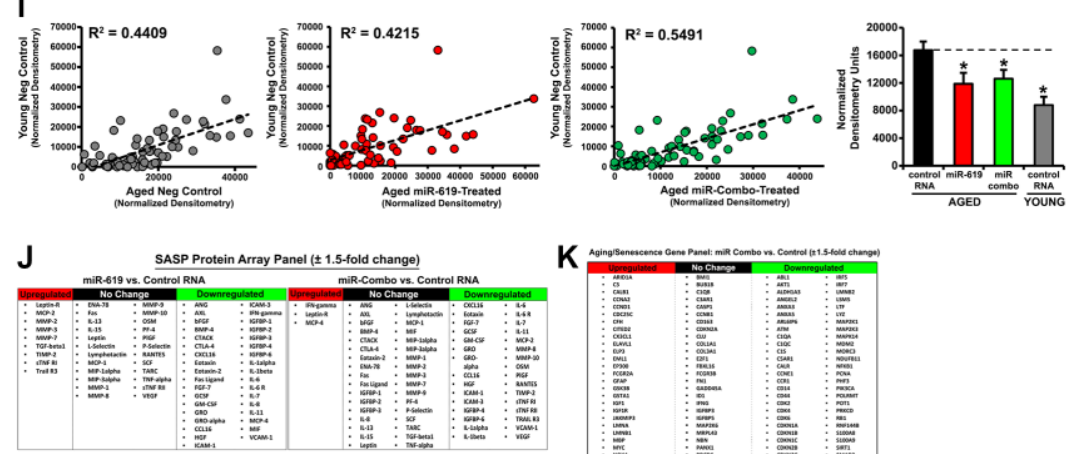

C

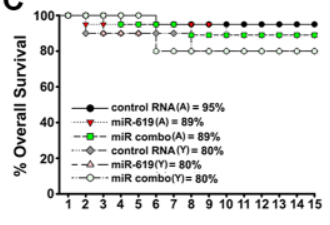

$\mathbf{F}$

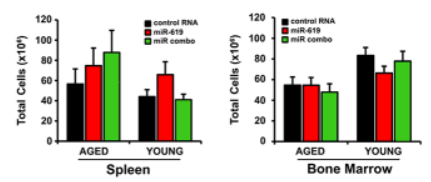

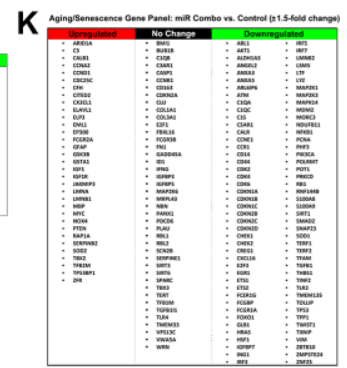

Supplementary Figure 5. Procedural and safety monitoring of humanized mice from with miRNA-mediated restoration. (A) Study design with 170 irradiated mice, transplanted with aged $(n=120)$ or young $(n=50)$ CD34+ cells, with $54 / 120$ mice successfully engrafted with aged, and 30/50 mice achieving chimera, based on $\geq 1 \%$ huCD45+ cells in blood. Mice displaying $0.5-1 \%$ chimera were enrolled in the saline treatment arms (not shown), and mice displaying $<0.5 \%$ chimera were not enrolled in the study. (B) Bleeds were performed on mice transplanted with aged ( $\mathrm{AO3}$ or $\mathrm{A04}$ ) and young donor ( $\mathrm{YO3}$ and $\mathrm{Y04}$ ) $\mathrm{CD}_{4} 4^{+}$cells, and chimera evaluated at 9- and 15weeks post-transplant. Average chimera of the aged (top graph) and young (bottom graph) donors enrolled in the study are shown. (C) Kaplan-Meier plot for huNSG overall survival post-treatment and (D) mouse body weights for the 15 weeks following the $2^{\text {nd }}$ transplant. Percent survival is displayed in the key (inset). (E) Mouse spleen weights at study endpoint, with representative spleen images at the top right of figure. Total (F) spleen and (G) bone marrow cellularity at study endpoint, mean \pm SEM. Histologic evaluation of tissues from huNSG treatment groups: At study endpoint, major organs and immune tissues were harvested. (G) H\&E staining of mouse spleen (top panels) and bone marrow (bottom panels), 4X magnification. (H) All harvested tissues were examined by a pathologist for tissue necrosis and tumorigenesis. Treatment groups were compared to age-matched control tissue for pathological comparison. Senescence- and agingrelated gene and protein expression in huNSG treatment groups from expanded study. (I) Scatterplots comparing senescence-associated secretory factor (SASF) expression in plasma of mice transplanted with either aged + negative control (gray dot plot), aged + miR-619 (red dot plot) or aged + miR-combo (green dot plot) cells compared to young control. Values are normalized by background subtraction of SASF levels in non-humanized control NSG mice. Results are presented as mean densitometry units, with average total SASF expression among each group also shown for comparison (far right bar graph). Enumeration of SASFs upregulated, downregulated or not changed for miR-619 vs. control (left Table) or miR-combo vs. control (right Table) is listed in '(J)'. (K) List of aging- and senescence-related genes whose expression is upregulated, downregulated or not changed in human cells isolated from huNSG BM in miR-combo treated mice vs. control. Classifications in ' $\mathrm{J}$ ' and ' $\mathrm{K}$ ' are based on a 1.5 -fold change cutoff. Results are presented as the mean \pm SEM. ${ }^{*} p \leq 0.05$ vs. control. 
A

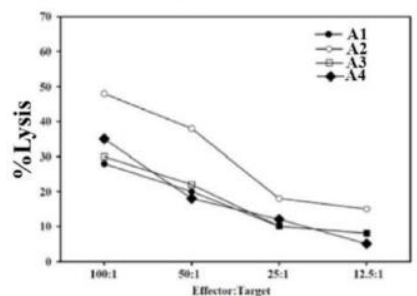

WEEK 2

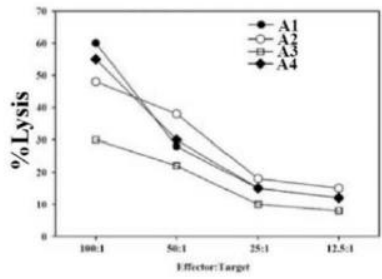

WEEK 4

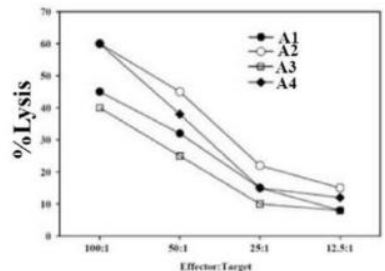

B

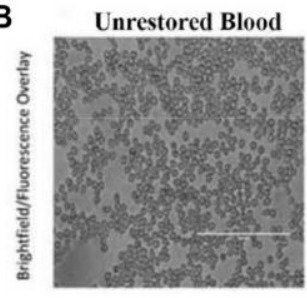

D

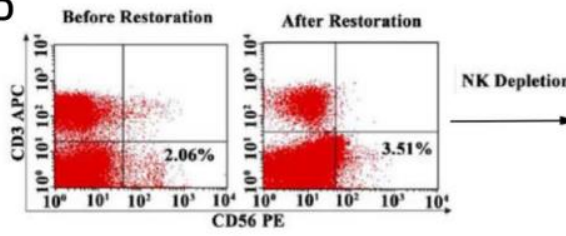

C

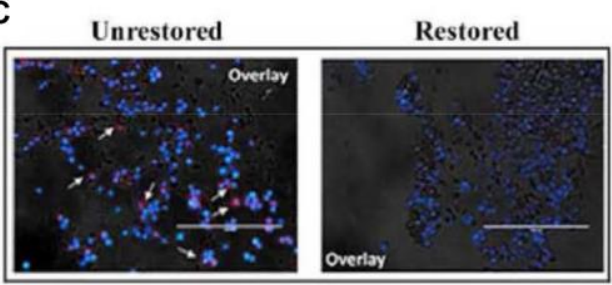

Red: Cytokeratin; Blue: DAPI

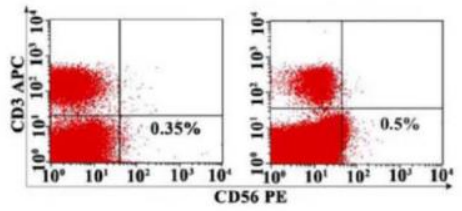

Supplementary Figure 6. (A) Timeline natural killer (NK) activity in restored age MPBs. NK activity was performed as described in Materials and Methods at day 1 and, wks 2 and 4 MPBs from heterochronic cultures. The results are shown for four donors, each restored with three different young MPBs. (B) Blood smears for GFP+ cells indicated undetectable GFP positivity in mice at 12 months posttransplant. GFP served as a surrogate of cancer stem cells. (C) Femurs from mice at 12 months after transplantation with restored or unrestored MPBs. The femurs were dissected longitudinally and then washed with PBS. The cells close to the endosteal regions were scraped and placed onto microscope slides, fixed with $1 \%$ paraformaldehyde and then labeled with rabbit anti- human pan cytokeratin $(1 / 1000)$ for human breast cancer cells and secondary labeling with PE-anti-mouse IgG. DAPI labeling for nuclear labeling of all cells. The slides were immediately imaged with the Evos fl2 auto imager. Representative images show the overlays of the labeled and bright field images at 100x magnification. (D) Representative results for CD56+ cells in restored and unrestored MPBs, with or without NK cell depletion. 


\section{Supplementary Table}

Supplementary Table 1. Mobilized Peripheral Blood (MPB) donor demographics.

\begin{tabular}{|c|c|c|c|c|c|c|c|}
\hline Donor ID & Age & Sex & Height (in) & Weight (lb) & Ethnicity & TNC Count $\left(10^{9}\right)$ & CD34 $^{+}$Count $\left(10^{6}\right)$ \\
\hline \multicolumn{8}{|c|}{ Old } \\
\hline A1 & 61 & $\mathrm{M}$ & 70 & 162 & Caucasian & 71.9 & 90.0 \\
\hline $\mathbf{A 2}$ & 60 & $\mathrm{M}$ & 70 & 190 & Caucasian & 43.6 & 185 \\
\hline $\mathbf{A 3}$ & 61 & $\mathrm{M}$ & 68 & 149 & Caucasian & 32.2 & 46.8 \\
\hline A4 & 61 & M & 67 & 172 & Caucasian & 47.0 & 93.9 \\
\hline A5 & 74 & $\mathrm{M}$ & NR & NR & Caucasian & $*$ & \\
\hline A6 & 66 & $\mathrm{M}$ & NR & NR & Caucasian & * & \\
\hline A7 & 68 & M & NR & NR & Caucasian & $*$ & \\
\hline A8 & 70 & M & NR & NR & Caucasian & * & \\
\hline \multicolumn{8}{|c|}{ Young } \\
\hline Y1 & 28 & M & 67 & 140 & $\begin{array}{c}\text { African } \\
\text { American }\end{array}$ & 42.2 & 354 \\
\hline Y2 & 22 & $\mathrm{M}$ & 66 & 146 & Hispanic & 79.2 & 192 \\
\hline Y3 & 20 & $\mathrm{M}$ & 67 & 160 & Caucasian & 45.5 & 200 \\
\hline Y4 & 20 & $\mathrm{~F}$ & 60 & 120 & Hispanic & 43.2 & 82.2 \\
\hline Y5 & 21 & $\mathrm{M}$ & 69 & 130 & Hispanic & 20.1 & 47.1 \\
\hline Y6 & 28 & $\mathrm{M}$ & NR & 138 & Caucasian & * & \\
\hline Y7 & 30 & $\mathrm{~F}$ & NR & 128 & Caucasian & * & \\
\hline Y8 & 29 & $\mathrm{M}$ & NR & 130 & Caucasian & $*$ & \\
\hline
\end{tabular}

Abbreviation: NR: Not recorded. ${ }^{*}$ Aliquots $(\sim 15-25 \mathrm{~mL})$ of mobilized peripheral blood donated for research.

Demographics of Umbilical Cord Blood (UCB)

\begin{tabular}{ccc}
\hline ID & UCB Volume $(\mathbf{m L})$ & Time $(\mathbf{h}):$ Delivery to Process \\
\hline UCB1 & 68 & 25 \\
UCB2 & 56 & 8 \\
UCB3 & 75 & 22 \\
UCB4 & 71 & 24 \\
UCB5 & 46 & 10 \\
UCB6 & 67 & 21 \\
UCB7 & 61 & 22 \\
UCB8 & 108 & 25 \\
UCB9 & 59 & 25 \\
UCB10 & 73 & 20 \\
\hline
\end{tabular}

Supplementary Video 1. Video showing entry of MV into cells.

Supplementary Video 2. Video showing MV entering cells. 